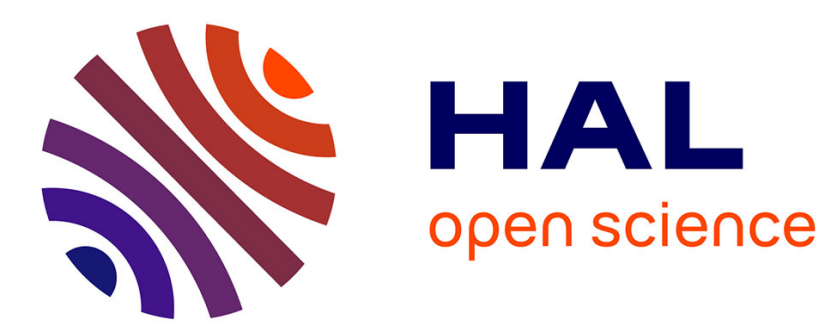

\title{
WILLINGNESS TO PAY OF AN EXPO-POWER UTILITY DECISION MAKER TO LIMIT CLIMATE CHANGE
}

\author{
Jules Sadefo-Kamdem, David Akame
}

\section{> To cite this version:}

Jules Sadefo-Kamdem, David Akame. WILLINGNESS TO PAY OF AN EXPO-POWER UTILITY DECISION MAKER TO LIMIT CLIMATE CHANGE. 2020. hal-02465195

\section{HAL Id: hal-02465195 \\ https://hal.umontpellier.fr/hal-02465195}

Preprint submitted on 3 Feb 2020

HAL is a multi-disciplinary open access archive for the deposit and dissemination of scientific research documents, whether they are published or not. The documents may come from teaching and research institutions in France or abroad, or from public or private research centers.
L'archive ouverte pluridisciplinaire HAL, est destinée au dépôt et à la diffusion de documents scientifiques de niveau recherche, publiés ou non, émanant des établissements d'enseignement et de recherche français ou étrangers, des laboratoires publics ou privés. 


\title{
WILLINGNESS TO PAY OF AN EXPO-POWER UTILITY DECISION MAKER TO LIMIT CLIMATE CHANGE
}

\author{
Jules SADEFO KAMDEM* \\ MRE EA 7491 (Université DE MontPellier) \\ DFR SJE (Université DE LA GuYANe) \\ David AKAME \\ MRE EA 7491 (Université MontPelLier)
}

January 24,2020

\begin{abstract}
This paper extends the work of Pindyck [1] by taking into consideration a large class family of different utility functions of economic agents. As in Pindyck [1], instead of considering a social utility function that is characterized by constant relative risk aversion (C.R.R.A), we use the expo-power utility function of Saha [2]. In fact, depending on the choice of the expo-power utility function parameters, we cover a diverse range ${ }^{1}$ of utility functions and besides covering the other utility functions that a C.R.R.A omits, Expo-power function permits us to discern if under the other behaviors of economic agents, the willingness to pay remains more affected by uncertain outcomes than certain outcomes, when we vary the expectation and standard deviation of the temperature distribution probability. Our paper has maintained the small-tailed gamma distributions of temperature and economic impact of Pindyck [1], not only because they hinder infinite future welfare losses (for an exponential utility function), but because it is easy to change some moments of the distribution (jointly or holding the others fixed) while studying how uncertainty influences the willingness to pay as explained in Pindyck [1].
\end{abstract}

Keywords: Willingness to Pay, Climate Change, Expo-Power Utility; I.A.R.A, D.A.R.A, I.R.R.A

JEL Codes: C12; C58; D52; G13; Q11; Q14

\footnotetext{
${ }^{*}$ Corresponding author: J. SADEFO KAMDEM, Université de Montpellier (Faculté d'économie) - Site de Richter, Avenue Raymond Dugrand, 34095 Montpellier cedex 2, email: jules.sadefo-kamdem@umontpellier.fr, jsadefo@gmail.com

${ }^{1}$ C.A.R.A, D.A.R.A, I.A.R.A, D.R.R.A and I.R.R.A except C.R.R.A .
} 


\section{Introduction}

Climate change is often described as the biggest environmental problem of the 21st century (Stern et al., 2006), although evidence is considered insufficient for some. According to the Intergovernmental Panel on Climate Change (IPCC), greenhouse gas (GHG) emissions from human activities, including the burning of fossil fuels such as coal, are "most likely" Temperature, changes in precipitation, and increasing variability in weather conditions. Without a coordinated policy around the world, advanced climate models predict that the average temperature in the United States for instance will increase by about 3 to 8 degree Faraday (1.7 to 4.4 degrees Celcius) by the end of the century, compared with today (IPCC 2007). In addition, the distribution of daily temperatures could be expected to increase in order to pose serious problems of individual or societal well-being, resulting in conflicts often due to starvation or, more generally, to the sharing of scarce resources diminished by climate change. Several direct and indirect economic consequences of climate change (climate damage) are: changes in crop yield, loss of land and capital due to rising sea levels, changes in fish catches, material damage caused by hurricanes, changes in labor productivity and health expenditures due to illness and heat stress; changes in tourism flows and energy demand for heating and cooling. Other important impacts of climate change are studied outside the modeling framework. One of the obvious consequences of climate change is the occurrence of more severe natural disasters, which are causing loss of human life not to mention their increasingly significant financial costs. To limit the negative consequences of climate change, scientists estimate that global warming can not exceed two degrees Celcius above the pre-industrial temperature. However, we are moving towards the critical threshold of 1.5 degrees Celcius . To limit global warming, we must reduce emissions of greenhouse gases by $80 \%$ to $95 \%$ by 2050 compared to the amount emitted in 1990. Many studies already show that this objective is achievable, but there is a need for urgent action at all levels. One must change the way a whole society works is anything but obvious. This usually requires a long-term effort on the part of the many sectors and actors that influence the way of life of this society. To implement meaningful changes, incentives are generally required. It is therefore essential that the political authorities take steps in this direction. Thus, several countries or insurance companies are asking the question: what is the willingness to pay today of an individual or society to avoid or be resilient faced with a temperature increase of 2 degrees Celcius compared to that of today ?

To this effect, as indicated in Pindyck [1] (which is our main reference for this paper), economic analyze of climate change policies often focus on "probable" scenarios - those within a confidence interval d About 66 - 90\% - for emissions, temperature, economic impacts and abatement costs. It would be difficult to justify the immediate adoption of a rigorous reduction policy in the light of these scenarios and the consensual estimates of discount rates and other relevant parameters. Indeed,Pindyck [1] wonders: 1) whether a rigorous policy can be justified by a cost-benefit analysis that distributes all possible results; And 2) whether the demand for reduction depends more on expected results or uncertainty about outcomes ?

Since, recent climate science and economic impact studies allow one to at least roughly estimate the distributions for temperature change and its economic impact. Pindyck (2012) show how these distributions can be incorporated in and affect conclusions from analyses of climate change policy. In its framework for policy analysis, Pindyck [1] estimates a simple measure of "willingness to pay" (WTP) that is the fraction of consumption $w^{*}(\tau)$ that an society would be willing to sacrifice, now and throughout the future, to ensure that any increase in temperature at a specific horizon $H$ is limited to $\tau$. Note that Pindyck [1] has focused only on the "demand side" of climate policy.

After a drawing on the current state of knowledge of global warming and its impact and the use of information on temperature change distributions based on scientific studies compiled by the IPCC, as well as information On the economic impacts of the recent "integrated assessment models" (IAMs), Pindyck [1] focuses on the gamma distribution for these variables. It models the economic impact as a relationship between temperature variation and the growth rate of GDP as opposed to its level. This distinction is justified by theoretical and empirical considerations and implies that 
global warming can have a permanent impact on future GDP. It then examines whether reasonable values for the remaining parameters (eg, initial growth rate and risk aversion index) can give values of $w^{*}(\tau)$ greater than $2 \%$ or $3 \%$ for Low values of $\tau$, which could favor a strict abatement. It also shows how $w^{*}(\tau)$ depends on the mean with respect to the standard deviation of the future temperature, and it calculates the iso-WTP-combinations of mean and standard deviations for which the WTP Is constant. This gives a further insight into how uncertainty drives WTP.

In the vein of Pindyck [1] and some of his references, we address the problem of calculating the willingness to pay to avoid an increase in the temperature of the tau order. Note that Pindyck [1] works under certain assumptions of which the two main ones we retain are that: 1) the variation of temperature over time follows an asymmetric gamma probability distribution, and 2) the society has a utility function of the CRRA type.

Our contribution is to say that a legal person, a society or a country does not necessarily have preferences in the face of climate change characterized by a type CRRA utility function. In fact, it is well-known that using CRRA framework imposes a specific restriction. At the end of the COP 21 in Paris, we noted that after the US presidential elections, the United States wanted to question its accession to the Paris agreement. It should be noted that more years ago, during previous conferences from Lima to Paris organized against climate change, several emerging countries (India, China, ... etc) were reluctant. This shows that climate change aversion can not easily be measured by constant risk aversion. With EU preferences, resistance to intertemporal substitution is constrained to be equal to relative risk-aversion. Note that resistance to substitution controls the attitude toward variations in consumption across time, under certainty. Also, risk-aversion controls the attitude toward variations in consumption across states of the world, at a given date. Moreover, we can mention that the modification of the curvature of the utility function makes substitution resistance and risk aversion move.

As an alternative, we adopt the expo-power utility function of Saha Saha [2], which is quite flexible and whose CRRA, DRRA, HRRA, CARRA, IRRA, DARA preferences can be identified according to the choice of the parameters. We arrive under our new assumption, all things equally otherwise as in Pindyck [1], highlighting a propensity to pay $w^{*}(\tau)$ which depends on the three parameters of Expo-Power utility function. .

Usually, when an economic analysis of climate change policy is conducted, it is made in 5 steps $^{2}$ which lead to reforms - even a stringent policy of abatement. In uncertainty, authorities sometimes face the dilemma of spending funds almost unnecessarily on programs of climatic reduction or do nothing and undergo the irreversible effects of climate change. In spite of this uncertainty (uncertainty on predictions or available forecasts), it remains nevertheless wise to adopt a perfect timing of preventive policy faced with irreversible risks. Although there are different views on the quickness in adopting a policy of reduction, (see, for example, for two period models,Kolstad [3] Fisher and Narain [4], and for multi-period models or with continuous time; Kolstad [5], Pindyck $[6,7]$ and Newell and Pizer [8]) for a consideration of irreversible effects, Pindyck [9] undertakes a study of the interaction between uncertainty and irreversibility in climate change policy.

Another approach of economic analysis (instead of the 5 conventional stages) is to calculate a measure

\footnotetext{
${ }^{2}$ According to Pindyck [1] : (1) Projections of future emissions of $\mathrm{CO}_{2}$ and equivalents (greenhouse gases) under a usual scenario of reduction policy, and estimations of future atmospheric concentrations of $\mathrm{CO}_{2}$. (2)Average or regional projections of temperature change which will result from strong concentrations of $\mathrm{CO}_{2}$. (3) Projections of G.D.P and consumption lost due to the high temperatures. (4) Estimations of the cost of greenhouse gas dejection for diverse concentrations. (5) Considerations on the social utility and the preferential time rate, in such a way of weighing the consumption lost by reduction face to benefits of consumption which will follow a reduced warming.
} 
of the willingness to pay ${ }^{3}$, like Pindyck [1], the fraction of consumption $w^{*}(\tau)$, that the society would be ready to sacrifice ${ }^{4}$ in order to ensure that any increase in temperature at a future time be limited at $\tau$, this, besides helping us solely focus on the influence of uncertainty and the ramifications thereof, will save us from having to make estimations of future concentrations of gases and costs of abatement.

This paper builds on the work of Pindyck [1] and takes into consideration different classes of utility of economic agents. Pindyck considers social utility through a C.R.R.A utility function and thanks to the expo-power utility function of Saha [2], we will consider, by a variation of parameters governing this function, all ${ }^{5}$ the utility range except C.R.R.A . Besides covering the other utility classes that a C.R.R.A omits, this function permits us to discern if under the other behavioral regimes of economic agents, the willingness to pay remains more affected by uncertain outcomes than certain outcomes when we vary the expectation and standard deviation of the temperature distribution.

Throughout the dissertation, unless otherwise specified, we will have the following abbreviations:

Throughout this paper, we maintain the small-tailed gamma distributions of temperature and economic impact of Pindyck, not only because they hinder infinite future welfare losses (for an exponential utility function), but because it is easy to change some moments of the distribution (jointly or holding the others fixed) while studying how uncertainty influences the willingness to pay as explained in Pindyck [1].

We calculate the W.T.P using an exponential utility function. Taking $\delta=0$ and $g_{0}=0.020, H=100$, and time $t$ going up to 500 years, we obtain values of $w^{*}(0)$ close to those obtained by Pindyck [1] ; about $2.5 \%$ for the DARA/DRRA class, $0.3 \%$ for the DARA/IRRA class, $0.025 \%$ for the CARA/IRRA and $0.015 \%$ for IARA/IRRA classes. In the averse classes, an increase of the utility discount rate leads to an increase of the W.T.P, even more, we have the two scenarios in the DARA/IRRA class for an $\alpha$ parameterization threshold ( $\beta$ held constant). For the least averse class, DARA/DRRA, we have the opposite and an increase of the utility discount rate produces a reduction of the W.T.P.

Uncertainty and climate policy; which, between uncertain and certain outcomes, have a greater influence on the W.T.P ?, to answer this question, we calculate the W.T.P for changes in expectation and the standard deviation of the temperature distribution (the parameter of economic impact held constant at its predicted value of 0.0001363 ). For the same value of W.T.P, we also calculate the corresponding expectation/standard deviation couple; as well, we calculate the sensitivity of the W.T.P with respect to changes in $\mathcal{E}(T)$ and $S D(T)\left(\partial w^{*} / \partial \mathcal{E}(T)\right.$ and $\left.\partial w^{*} / \partial S D\right)$ and for all these different cases, treating expectation and standard deviation as economic goods, we calculate the marginal rate of substitution, $M . R . S=-\left(\partial w^{*} / \partial S D\right) /\left(\partial w^{*} / \partial \mathcal{E}(T)\right)$, to unveil social preferences.

In what follows, in section 2, we explain the methodology and its relationship with that of Pindyck [1]. Section 3 recalls the work of Pindyck and the inherent conclusions. Section 4 considers the work of Pindyck from another angle, changing the C.R.R.A utility function for the Expo-power of Saha [2] and shows the values of W.T.P and its parameterization obtained for this change. Section 5 summarizes the findings and provides future prospects. In section 6 , we give the conclusion of our paper.

\footnotetext{
${ }^{3}$ Throughout this paper will carry the abbreviation W.T.P .

${ }^{4}$ That this proportion of consumption be enough to limit the future temperatures at $\tau$ is not the purpose of the analysis, but to discern the willingness of the agents.

${ }^{5}$ C.A.R.A, D.A.R.A, I.A.R.A, D.R.R.A and I.R.R.A except C.R.R.A .
} 


\begin{tabular}{|c|c|}
\hline Abbreviation & Meaning \\
\hline W.T.P & Willingness to pay. \\
\hline$w^{*}(\tau)$ & $\begin{array}{l}\text { fraction of consumption that society would be willing to sacrifice to ensure that } \\
\text { any increase in temperature at a future point be limited to } \tau \text {; Also W.T.P. }\end{array}$ \\
\hline $\mathcal{E}$ & expectation/mean of distribution. \\
\hline$S D$ & Standard deviation of distribution. \\
\hline$T_{t}$ & temperature at time $t$. \\
\hline$T_{H}$ & temperature at the horizon $H$. \\
\hline$t$ & time. \\
\hline G.D.P & Gross Domestic Product. \\
\hline$g_{0}$ & Initial G.D.P rate. \\
\hline$\delta$ & Utility disount rate. \\
\hline$\eta$ & Index of risk-aversion. \\
\hline$\alpha, \beta$ & Parameters giving index of risk aversion in the exponential utility function. \\
\hline$W$ & Social welfare. \\
\hline$T$ & Parameter of temperature distribution. \\
\hline$\gamma$ & Parameter of economic-impact distribution (temperature on G.D.P.) . \\
\hline$L(T)$ & Loss function (of G.D.P due to temperature T.) . \\
\hline
\end{tabular}

Table 1.1: List of abbreviations.

\section{Pindyck (2012) Background Revisited and methodology}

We resume the modeling of Pindyck (see Pindyck [1],291 - 293), and we introduce the exponential utility function:

$U\left(C_{t}\right)=\theta-e^{-\beta C_{t}^{\alpha}}, \theta>1, \alpha \neq 0, \beta \neq 0, \alpha \beta>0$.

that we use to calculate the fraction of consumption $w^{*}(\tau)$, that society would be willing to sacrifice to ensure that any increase in temperature at a future point be limited to $\tau$; this fraction, $w^{*}(\tau)$, is a measure of the willingness to pay, W.T.P .

employing the consumption model of Pindyck, 


$$
C_{t}=\exp \left\{-\frac{2 \gamma H T_{H}}{\ln (1 / 2)}+\left(g_{0}-2 \gamma T_{H}\right) t+\frac{2 \gamma H T_{H}}{\ln (1 / 2)}(1 / 2)^{t / H}\right\} .
$$

If, $T_{H}$ and $\gamma$ were known, social-welfare would be given by;

$$
W=\int_{0}^{\infty} U\left(C_{t}\right) e^{-\delta t} d t
$$

where,

$$
\left.U\left(C_{t}\right) e^{-\delta t}=\theta e^{-\delta t}-e^{-\delta t-\beta \exp \left\{-\frac{2 \alpha \gamma H T_{H}}{\ln (1 / 2)}+\left(g_{0}-2 \gamma T_{H}\right) \alpha t+\frac{2 \alpha \gamma H T_{H}}{\ln (1 / 2)}(1 / 2)^{t / H}\right.}\right\} .
$$

If we assume that society sacrifices a fraction $w^{*}(\tau)$ of the present and future consumption to ensure that $T_{H} \leq \tau$, with uncertainty at time $t=0$, social welfare would be given by;

$$
W_{1}(\tau)=\left[\theta-e^{-\beta\left(1-w^{*}(\tau)\right)^{\alpha}}\right] \mathcal{E}_{0, \tau} \int_{0}^{\infty} U\left(C_{t}\right) e^{-\delta t} d t .
$$

where, $\mathcal{E}_{0, \tau}$ is the conditional expectation at $t=0$ using the distributions of $T_{H}$ and $\gamma$, conditioned by $T_{H} \leq \tau$.

If no sacrifice of consumption is made, social welfare would be given by;

$$
W_{2}=\left[\theta-e^{-\beta}\right] \mathcal{E}_{0} \int_{0}^{\infty} U\left(C_{t}\right) e^{-\delta t} d t .
$$

where, $\mathcal{E}_{0}$ like before, is the expectation at $t=0$ using the distributions of $T_{H}$ and $\gamma$, but without any conditioning on $T_{H}$. The W.T.P to keep $T_{H} \leq \tau$, is calculated as the quantity $w^{*}(\tau)$, which will assert equivalence between $W_{1}(\tau)$ et $W_{2}$.

\subsection{The case of a C.R.R.A utility function: the work of R.S. Pindyck}

Professor Robert S. Pindyck conducts a study of uncertainty in climate change policy, he demonstrates how the W.T.P is more affected by uncertain outcomes ${ }^{6}$ (standard-deviation instead of expected mean temperature from temperature distribution) and suggests that a better understanding of the uncertainty in temperature distributions and economic impact (in the I.P.C.C studies and others) could lead to stronger W.T.P predictions, more reliable and possibly a better climate policy. Throughout he uses a C.R.R.A utility function. In what follows, we resume the key points in Pindyck [1] and later we will modify the C.R.R.A utility function.

According to his $\operatorname{model}^{7}$, temperature follows;

$$
T_{t}=2 T_{H}\left[1-\left(\frac{1}{2}\right)^{\frac{t}{H}}\right]
$$

the G.D.P growth model is,

$$
g_{t}=g_{0}-\gamma T_{t}
$$

\footnotetext{
${ }^{6}$ He generates a table of mean/standard-deviation couples which produce the same W.T.P, and even for high expected mean temperature, he finds the corresponding standard deviation low, altogether producing the same W.T.P, which demonstrates how certainty on the predicted mean temperature is more useful to society than the mean temperature in itself.

${ }^{7}$ This model allows a doubling of temperature as $t \rightarrow \infty$, which is in accordance with the I.P.C.C [10, 11, 12].
} 
or, by (2.1.1), we have,

$$
g_{t}=g_{0}-\gamma 2 T_{H}\left[1-\left(\frac{1}{2}\right)^{\frac{t}{H}}\right]
$$

at the horizon $H$, the G.D.P is G.D.P $P_{H}$, but as we suppose slight losses (for a negative growth rate $g_{t}$ ), it is nevertheless updated and indeed is $L(T) G . D . P_{H}$, where $L(T)$ is the loss function (such that at the horizon $H$, for time $t$, the percentage of G.D.P lost due to excess temperature $T$ is $1-L(T)$ ). Throughout we will use the loss function $L(T)=e^{-\beta T^{2}}$ and the consumption $C_{t}{ }^{8}$, is given by,

$$
C_{t}=e^{\int_{0}^{t} g(s) d s}=\exp \left\{-\frac{2 \gamma H T_{H}}{\ln (1 / 2)}+\left(g_{0}-2 \gamma T_{H}\right) t+\frac{2 \gamma H T_{H}}{\ln (1 / 2)}(1 / 2)^{t / H}\right\}
$$

and the relation $\gamma / \beta^{9}$ becomes $\gamma=\frac{\ln (2)}{2 \ln (2)-1} \frac{\beta T}{H}$.

The utility function is $U\left(C_{t}\right)=\frac{C_{t}^{\eta}}{1-\eta}$, such that welfare is calculated as:

$$
W=\int_{0}^{\infty} U\left(C_{t}\right) e^{-\delta t} d t=\frac{1}{1-\eta} \int_{0}^{\infty} e^{\omega-\rho t-\omega\left(\frac{1}{2}\right)^{\frac{t}{H}}} d t
$$

with

$$
\begin{aligned}
& \rho=(\eta-1)\left(g_{0}-2 \gamma T_{H}\right)+\delta \\
& \omega=2(\eta-1) \gamma H T_{H} / \ln (1 / 2)
\end{aligned}
$$

The I.P.C.C [10] study foresaw temperature increases of 2 to 4.5 with an expectation of $3.0^{\circ} \mathrm{C}$, and the values predicted in more recent studies like the I.P.C.C [13] maintain predictions of the same order due to reforms already in place to limit greenhouse gases. Weitzman [14], has percentile estimations of $17 \%$ probability that the doubling of $\mathrm{CO}_{2}$ concentration would lead to a $4.5^{\circ} \mathrm{C}$ growth of mean temperature, probability of $5 \%$ for a growth of $\geq 7.0^{\circ} \mathrm{C}$, and a probability of $1 \%$ for an increase of $\geq 10.0^{\circ} \mathrm{C}$. In using these 3 percentiles, Pindyck fits a shifted gamma temperature distribution.

This shifted gamma distribution, is the $\theta$-shifted gamma distribution:

$$
f(x ; r, \lambda, \theta)=\frac{\lambda^{r}}{\Gamma(r)}(x-\theta)^{r-1} e^{-\lambda(x-\theta)}, x \geq \theta .
$$

with $\Gamma(r)=\int_{0}^{\infty} s^{r-1} e^{-s} d s$. Obtaining $r=3.8, \lambda=0.92$, and $\theta=-1.13$.

Also, for the distribution of economic-impact (impact of temperature on G.D.P), we first find a distribution for $\beta$ in the loss function $L(T)=e^{-\beta T^{2}}$, and we use the relation $\gamma=\frac{\ln (2)}{2 \ln (2)-1} \frac{\beta T}{H}$, to get the $\gamma$ distribution.

According to the I.P.C.C [11], global G.D.P losses average 1-5\%, for a $4^{\circ} \mathrm{C}$ warming, according to Dietz and Stern [15] 0.5-2\% of G.D.P lost due to $T=3^{\circ} C$, and $1-8 \%$ for $T=5^{\circ} C$. Standing on

\footnotetext{
${ }^{8}$ with $C_{0}=1$.

${ }^{9} C_{t}=e^{\int_{0}^{t} g(s) d s}=\exp \left\{-\frac{2 \gamma H T_{H}}{\ln (1 / 2)}+\left(g_{0}-2 \gamma T_{H}\right) t+\frac{2 \gamma H T_{H}}{\ln (1 / 2)}(1 / 2)^{t / H}\right\}$ but in fact, $C_{t}=L\left(T_{t} e^{\int_{0}^{t} g_{0} d s}\right.$, since $L(T)=$ $e^{-\beta T^{2}}$, at horizon $H$,

$$
C_{H}=\exp \left\{-\frac{2 \gamma H T_{H}}{\ln (1 / 2)}+\left(g_{0}-2 \gamma T_{H}\right) H+\frac{\gamma H T_{H}}{\ln (1 / 2)}\right\}=e^{-\beta T_{H}^{2}} e^{g_{0} H}
$$
}

, which implies that $\gamma=\frac{\ln (2)}{2 \ln (2)-1} \frac{\beta T}{H}$. 


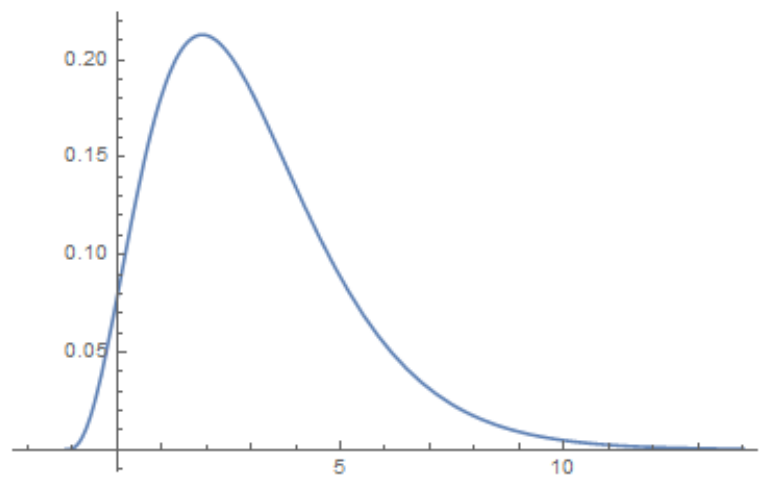

Figure 2.1: Temperature distribution $\left(\mathcal{E}(T)=3.0^{\circ} C, r=3.8, \lambda=0.92\right)$

the appellation of the I.P.C.C of "most likely" which designates a confidence interval of $66 \%$, it is possible to build 3 percentiles from [1-5]: let 0.17 correspond to 1, 0.50 correspond to 3 and 0.83 to 5 , such that all this makes a confidence interval of $83 \%-17 \%=66 \%$, for a $4^{\circ} \mathrm{C}$ warming. We now use $^{10}$ the relation $\gamma / \beta$ to have the percentiles $\mathcal{E}(\gamma)=0.0001363$ (corresponding to a $50 \%$ probability), $\gamma_{1}=0.0000450(17 \%)$ and $\gamma_{2}=0.0002265(83 \%)$. Then we fit a shifted gamma distribution on these three percentiles and we get $r=4.5, \lambda=21,341$ and $\theta=\mathcal{E}(\gamma)-\frac{r}{\lambda}=-0.0000746$.

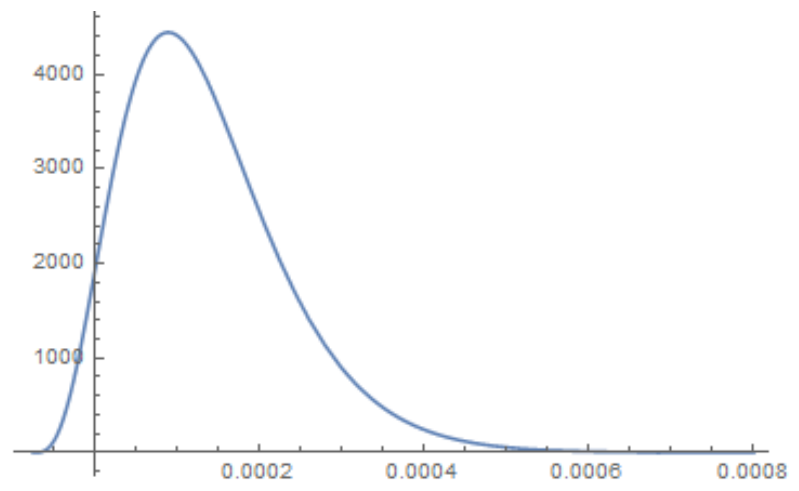

Figure 2.2: Economic-impact distribution $(\mathcal{E}(\gamma)=0.0001363, r=4.5, \lambda=21,341)$

Now that we have the parameters for the temperature and economic-impact distributions, everything makes sense and (2.1.5) is well defined. W.T.P is calculated as the quantity $w^{*}(\tau)$ which will assert equivalence between the constrained welfare expectation (under a consumption reduced of $w^{*}(\tau) \%$, temperature distribution censured ${ }^{11}$ en $\tau$ and that of economic-impact unchanged) and the unconstrained welfare expectation (under total consumption, of $100 \%$, and the distributions as estimated above).

\footnotetext{
${ }^{10} \gamma=\frac{\ln (2)}{2 \ln (2)-1} \frac{\beta T}{H}$, which implies that $\beta T^{2}=\frac{2 \ln (2)-1}{\ln (2)} H T \gamma$. Since for $L \%$ of lost G.D.P, $1-L=\exp \left[-\beta T^{2}\right]=$ $\exp [-0.557 H T \gamma]$, for $H=100, T=4^{\circ} C, 0.97=e^{-223.5 \mathcal{E}(\gamma)}, 0.99=e^{-223.5 \gamma_{1}}, 0.95=e^{-223.5 \gamma_{2}}$.

${ }^{11}$ we divide by $\int_{\theta_{T}}^{\tau} f(T) d T$ so that it remains a density.
} 
We have,

$$
\begin{gathered}
\frac{\left[1-w^{*}(\tau)\right]^{1-\eta}}{1-\eta} \int_{0}^{\infty}\left\{\frac{1}{F(\tau)} \int_{\theta_{T}}^{\tau} \int_{\theta_{\gamma}}^{+\infty} e^{\omega-\rho t-\omega\left(\frac{1}{2}\right)^{\frac{t}{H}}} f(T) g(\gamma) d T d \gamma\right\} d t \\
=\frac{1}{1-\eta} \int_{0}^{\infty}\left\{\int_{\theta_{T}}^{+\infty} \int_{\theta_{\gamma}}^{+\infty} e^{\omega-\rho t-\omega\left(\frac{1}{2}\right)^{\frac{t}{H}}} f(T) g(\gamma) d T d \gamma\right\} d t
\end{gathered}
$$

with $F(\tau)=\int_{\theta_{T}}^{\tau} f(T) d T, \theta_{T}, \theta_{\gamma}$ the lower limits of the temperature and economic-impact distributions, $\rho$ and $\omega$ as in (2.1.6) and (2.1.7).

which implies that $w^{*}(\tau)$ is given by;

$$
w^{*}(\tau)=1-\left(\frac{\int_{0}^{\infty}\left\{\int_{\theta_{T}}^{+\infty} \int_{\theta_{\gamma}}^{+\infty} e^{\omega-\rho t-\omega\left(\frac{1}{2}\right)^{\frac{t}{H}}} f(T) g(\gamma) d T d \gamma\right\} d t}{\int_{0}^{\infty}\left\{\frac{1}{F(\tau)} \int_{\theta_{T}}^{\tau} \int_{\theta_{\gamma}}^{+\infty} e^{\omega-\rho t-\omega\left(\frac{1}{2}\right)^{\frac{t}{H}}} f(T) g(\gamma) d T d \gamma\right\} d t}\right)^{\frac{1}{1-\eta}} .
$$

\subsubsection{Certainty on temperature and its economic impact}

Supposing that temperature follows with certainty (2.1.1), and that the economic parameter is constant at its predicted mean of $\mathcal{E}(\gamma)=0.0001363$, we have;

$$
\frac{\left[1-w^{*}(\tau)\right]^{1-\eta}}{1-\eta} \quad \int_{0}^{\infty} e^{\omega_{\tau}-\rho_{\tau} t-\omega_{\tau}\left(\frac{1}{2}\right)^{\frac{t}{H}}} d t \quad=\quad \frac{1}{1-\eta} \int_{0}^{\infty} e^{\omega-\rho t-\omega\left(\frac{1}{2}\right)^{\frac{t}{H}}} d t
$$

where $\rho$ and $\omega$ are given by (2.1.6) and (2.1.7), and $\rho_{\tau}$ and $\omega_{\tau}$ (due to $w^{*}(\tau) \%$ of sacrificed consumption) are given by;

$$
\begin{aligned}
\rho_{\tau} & =(\eta-1)\left(g_{0}-2 \tau \mathcal{E}(\gamma)\right)+\delta \\
\omega_{\tau} & =2 \tau H(\eta-1) \mathcal{E}(\gamma) / \ln (1 / 2)
\end{aligned}
$$

and the W.T.P is calculated as;

$$
w^{*}(\tau)=1-\left(\frac{\int_{0}^{\infty} e^{\omega-\rho t-\omega\left(\frac{1}{2}\right)^{\frac{t}{H}} d t}}{\int_{0}^{\infty} e^{\omega_{\tau}-\rho_{\tau} t-\omega_{\tau}\left(\frac{1}{2}\right)^{\frac{t}{H}} d t}}\right)^{\frac{1}{1-\eta}} .
$$

\subsubsection{Uncertainty on temperature and its economic impact}

In the case of uncertainty, we use the temperature distribution, $f(T)$, and economic-impact distribution $g(\gamma)$, obtained higher to calculate the W.T.P as in (2.1.10). 


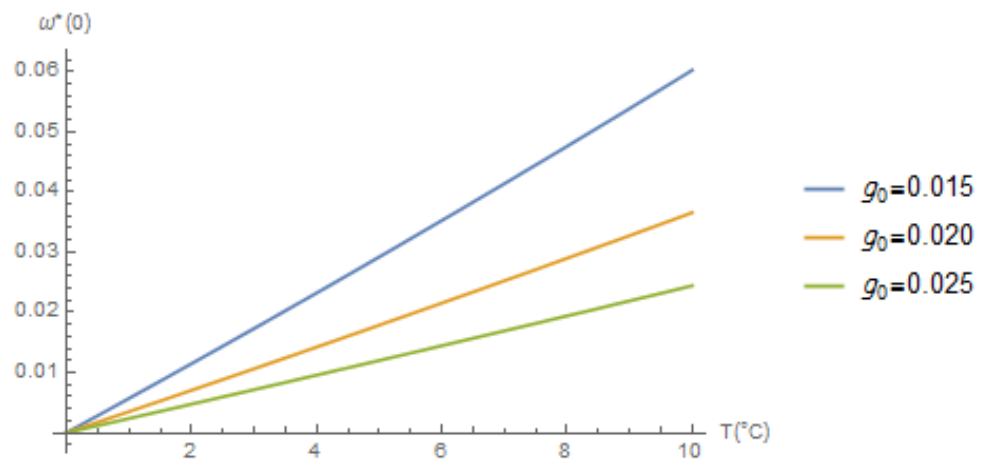

Figure 2.3: W.T.P and temperature change $T_{H}, \eta=2, g_{0}=0.015,0.020,0.025, \delta=0$.

\subsection{Influences on W.T.P}

\subsubsection{The case of certainty: W.T.P and $T_{H}$.}

Temperature follows $T_{t}=2 T_{H}\left[1-\left(\frac{1}{2}\right)^{\frac{t}{H}}\right]$, varying the W.T.P for values of $T_{H}$ at the horizon $H=100$, we have in the figure, a calculation of $w^{*}(0)$, the willingness to pay to keep $T_{t}$ nil, with the parameters; $\eta=2, g_{0}=0.015,0.020,0.025, \delta=0$. W.T.P increases proportionally to $T_{H}$ and inversely to $g_{0}$, which means that a smaller initial G.D.P growth rate would imply a greater W.T.P . According to Pindyck, the more $g_{0}$ is small, the more we get a low consumption discount rate, which will produce a greater W.T.P .

\subsubsection{The case of uncertainty: W.T.P and $\tau$.}

In the case of uncertainty, everything is calculated as an expectation using the distributions of temperature and economic-impact, and the W.T.P is given by (2.1.10). The following figure calculates W.T.P with the values; $\eta=1.5$ et $2, g_{0}=0.015,0.020,0.025$ and $\delta=0$. W.T.P is inversely proportional to $\tau, \eta$ and $g_{0}$.

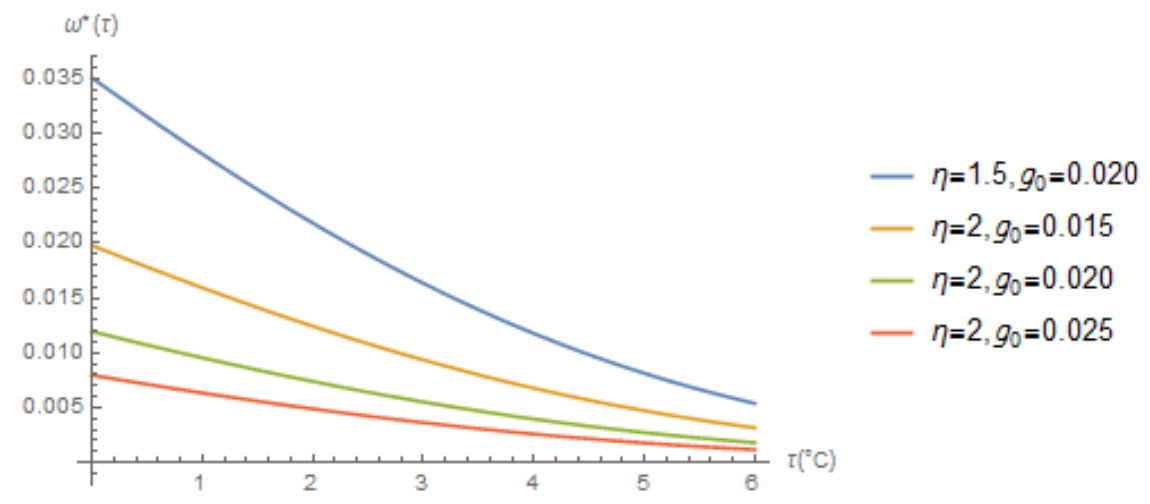

Figure 2.4: W.T.P, $T$ and $\gamma$ uncertain, $\eta=1.5$ and $2, g_{0}=0.015,0.020,0.025, \delta=0$.

According to the figure, consumers (with an index of risk aversion, $\eta$ of 2 , and with an initial growth-rate, $g_{0}$ of 0.020 ) would be ready to sacrifice about $2 \%$ of consumption to ensure that the increase of temperature be nil. 


\subsubsection{The case of uncertainty: W.T.P and $\eta$.}

Figure 2.5 shows the relation between $w^{*}(3)$ and $\eta$. W.T.P is inversely proportional to $\eta$ and $\delta$, although under another temperature distribution with a higher mean, the W.T.P would be greater. We have the parameters; $\tau=3, g_{0}=0.020, \delta=0$ and 0.01 .

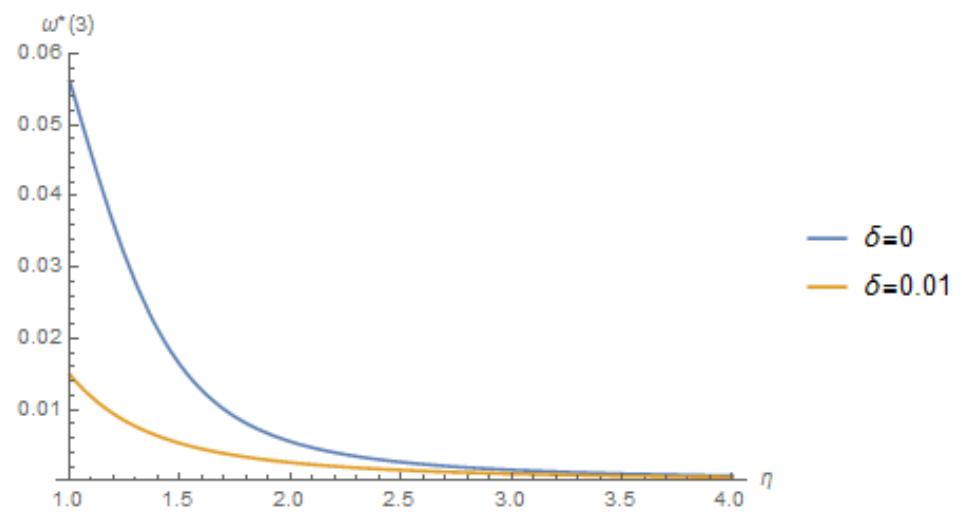

Figure 2.5: W.T.P and $\eta$ for $\tau=3, g_{0}=0.020, \delta=0$ and 0.01 .

Similarly (but in this case, $\eta^{12}$ and not $g_{0}$ ) as above, the more $\eta$ is small (nearing 1 ), we have greater W.T.P values, but as soon as $\delta$ increases (be it just of 0.01 ), W.T.P is considerably reduced to less than $2 \%$.

In Figure 2.6, the mean of the temperature distribution is increased to, $\mathcal{E}\left(T_{H}\right)=5.0^{\circ} C$, and we have, for the same parameters as before, greater W.T.P values.

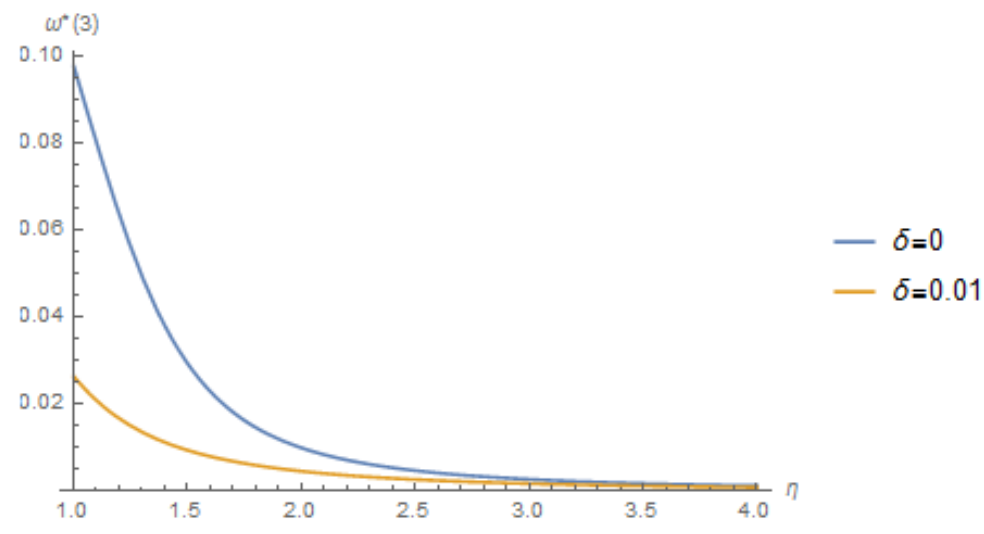

Figure 2.6: W.T.P and $\eta$ for $\tau=3, \mathcal{E}\left(T_{H}\right)=5^{\circ} C, g_{0}=0.020, \delta=0$ and 0.01 .

\subsection{Discussion and comments}

To justify ${ }^{13}$ his choice of the G.D.P growth rate in the modeling of the economic impact, taking into consideration the relation between temperature and the rate, instead of the growth level of the G.D.P, Pindyck in Pindyck [16], conducts a comparative study of the two considerations, and obtains almost similar values of W.T.P. It could also be the case that the low weight of distribution tails underestimate the probability of catastrophic events (strong temperature increases beyond its

\footnotetext{
${ }^{12}$ In Ramsey's growth model, the consumption discount rate is given by $R_{t}=\eta g_{t}+\delta$, so a small G.D.P growth rate, $g_{0}$ (or index $\eta$, for a given $\delta$ ) will produce a small consumption discount rate and thus consumers would be more inclined to sacrifice a fraction of their present and future consumption.

${ }^{13}$ This choice might underestimate G.D.P losses .
} 
expectation or great G.D.P losses beyond predictions of the economic impact distribution) and thus underestimating the W.T.P, but in Pindyck [17], Pindyck shows that so far as the marginal utility is bounded, these events disappear and a small-tailed distribution could produce greater W.T.P values than a thick-tailed distribution.

When he gets small W.T.P values (even for an utility discount rate of zero, $\delta=0$.) This is due to the low weight of the distribution tails and the fact that the corresponding consumption discount rate $\left(\eta g_{0}\right)$ is also low, and losses at the horizon $H=100$ years, are very low in the early years. For the C.R.R.A agent, if we want to have strong W.T.P values, we must be limited to small values of the index of risk aversion $(\eta<1.5)$, small G.D.P growth rate $\left(g_{0}<0.020\right)$ and a nil utility discount rate, $\delta=0$.

For a variation of parameters ${ }^{14}$, Pindyck obtains values of $w^{*}(0)$ (the willingness to pay to limit the increase of temperature at 0 ) around $2 \%$, and far below $2 \%$ (around $1 \%$ ) in the case of limiting the increase of temperature to the predicted value of the I.P.C.C of $3^{\circ} \mathrm{C}$. The mean and the standard deviation of the temperature distribution vary, and one at a time (holding the other constant each time), he calculates the W.T.P. He also calculates the corresponding mean/standard deviation couple producing the same W.T.P .

All through, the marginal rate of substitution obtained is larger for small values of standard deviation and considerably larger means; which means that uncertainty on temperature (from the economic agents' point of view) is more important than certainty in terms of welfare; is a greater driving force of W.T.P, and thus of climate policy. A W.T.P value of $2 \%$ is small but does not mean that an abatement policy should not ensue; considering only $2 \%$ of the G.D.P for a country in terms of monetary value, if not $1 \%$ to limit the increase to its predicted value of $3^{\circ} \mathrm{C}$, this is a good investment.

\section{The Model with the Saha Expo-Power Utility Function}

Most economic agents do not exhibit a constant utility. The utility function we use is at the same time D.R.R.A, I.R.R.A, D.A.R.A, C.A.R.A and I.A.R.A (by a variation of parameters); except C.R.R.A ${ }^{15}$, and as such is a complement to the work of Pindyck [1]. We use the utility function introduced by Saha [2],

$$
U\left(C_{t}\right)=\theta-e^{-\beta C_{t}^{\alpha}}, \theta>1, \alpha \neq 0, \beta \neq 0, \alpha \beta>0 .
$$

We have, by a variation of parameters,

\begin{tabular}{lccc}
\hline & DRRA & CRRA & IRRA \\
\hline DARA & $\alpha<0, \beta<0$ & $\mid$ & $0<\alpha<1, \beta>0$ \\
CARA & $\mid$ & $\mid$ & $\alpha=1, \beta>0$ \\
IARA & $\mid$ & $\mid$ & $\alpha>1, \beta>0$ \\
\hline
\end{tabular}

Table 3.1: Classification of the exponential utility function in terms of $\alpha, \beta$.

lets put, for $U\left(C_{t}\right) e^{-\delta t}$ given by $(2.0 .3)$,

\footnotetext{
${ }^{14}$ See Pindyck [1],pages 299 and 300.

${ }^{15}$ We note that $R^{\prime}(w)=A(w)+w A^{\prime}(w)$, and if our utility function is already C.A.R.A, we have $A^{\prime}(w)=0$, and $R^{\prime}(w)=A(w)=$ constant $\neq 0$. So an utility function cannot be at the same time C.A.R.A and C.R.R.A .
} 


$$
\begin{gathered}
M_{\tau}(t)=\frac{1}{F(\tau)} \int_{\theta_{T}}^{\tau} \int_{\theta_{\gamma}}^{+\infty} U\left(C_{t}\right) e^{-\delta t} f(T) g(\gamma) d T d \gamma \\
M_{\infty}(t)=\int_{\theta_{T}}^{+\infty} \int_{\theta_{\gamma}}^{+\infty} U\left(C_{t}\right) e^{-\delta t} f(T) g(\gamma) d T d \gamma .
\end{gathered}
$$

with $F(\tau)=\int_{\theta_{T}}^{\tau} f(T) d T, \theta_{T}, \theta_{\gamma}$ the lower limits of the distributions of temperature and economic-impact.

Proceeding like before, to find the willingness to pay,

$$
\begin{aligned}
{\left[\theta-e^{-\beta\left(1-w^{*}(\tau)\right)^{\alpha}}\right] \int_{0}^{\infty} M_{\tau}(t) d t=\left[\theta-e^{-\beta}\right] \int_{0}^{\infty} M_{\infty}(t) d t } & \\
& {\left[\theta-e^{-\beta\left(1-w^{*}(\tau)\right)^{\alpha}}\right] G_{\tau}=\left[\theta-e^{-\beta}\right] G_{\infty} . }
\end{aligned}
$$

and the W.T.P is given by;

$$
w^{*}(\tau)=1-\left(-\frac{1}{\beta} \ln \left\{\theta-\left[\theta-e^{-\beta}\right] \frac{G_{\infty}}{G_{\tau}}\right\}\right)^{1 / \alpha} .
$$

\subsection{Certainty on temperature and its economic impact}

In the case of certainty, temperature follows $T_{t}=2 T_{H}\left[1-\left(\frac{1}{2}\right)^{\frac{t}{H}}\right]$, and the parameter of economic impact is constant at $\gamma=\mathcal{E}(\gamma)=0.0001363$. As a result of $w^{*}(\tau) \%$ of consumption sacrificed, at time $t$, at the horizon $H$ (because $T_{H} \leq \tau$ ), $C_{t}$ takes the form,

$C_{t}=\exp \left\{-\frac{2 \gamma H \tau}{\ln (1 / 2)}+\left(g_{0}-2 \gamma \tau\right) t+\frac{2 \gamma H \tau}{\ln (1 / 2)}(1 / 2)^{t / H}\right\}$

put,

$$
\begin{aligned}
\xi_{\tau} & =\frac{2 \gamma H \tau}{\ln (1 / 2)}, \\
\zeta_{\tau} & =g_{0}-2 \gamma \tau .
\end{aligned}
$$

to calculate the W.T.P, we have;

$$
\begin{aligned}
{\left.\left[\theta-e^{-\beta\left(1-w^{*}(\tau)\right)^{\alpha}}\right] \int_{0}^{\infty}\left(\theta e^{-\delta t}-e^{-\delta t-\beta \exp \left\{-\alpha \xi_{\tau}+\alpha \zeta_{\tau} t+\alpha \xi_{\tau}(1 / 2)^{t / H}\right.}\right\}\right) d t } \\
=\left[\theta-e^{-\beta}\right] \int_{0}^{\infty}\left(\theta e^{-\delta t}-e^{-\delta t-\beta \exp \left\{-\alpha \xi+\alpha \zeta t+\alpha \xi(1 / 2)^{t / H}\right\}}\right) d t \\
{\left[\theta-e^{-\beta\left(1-w^{*}(\tau)\right)^{\alpha}}\right] I_{\tau}=\left[\theta-e^{-\beta}\right] I_{T_{H}} . }
\end{aligned}
$$

with $\xi=\frac{2 \gamma H T_{H}}{\ln (1 / 2)}, \zeta=g_{0}-2 \gamma T_{H}$ under a full consumption regime. 
We then have in this case that $w^{*}(\tau)$ is given by;

$$
w^{*}(\tau)=1-\left(-\frac{1}{\beta} \ln \left\{\theta-\left[\theta-e^{-\beta}\right] \frac{I_{T_{H}}}{I_{\tau}}\right\}\right)^{1 / \alpha} .
$$

\subsection{Uncertainty on temperature and its economic impact}

In the case of uncertainty, like in Pindyck [1], everything is calculated as an expectation using the distributions of temperature and economic impact, and the W.T.P is given by (3.0.5) .

\subsection{Influences on W.T.P : the case of certainty.}

In the case of certainty, temperature follows $T_{t}=2 T_{H}\left[1-\left(\frac{1}{2}\right)^{\frac{t}{H}}\right]$ and varying the W.T.P for values of $T_{H}$ at the horizon $H=100$, we have in the figures which follow $w^{*}(0)$, the willingness to pay to keep $T_{t}$ nil according to the different utility classes. We vary the parameters $\alpha, \beta, \theta^{16}, g_{0}$ and $\delta$, and i study how these affect the W.T.P .

\subsubsection{W.T.P and $T_{H}$ : the case D.A.R.A and D.R.R.A: $\alpha<0, \beta<0$.}

This category represents the least risk averse agents, and with parameter values of $\alpha=-0.3, \beta=-3.55$, $\theta=2.33, g_{0}=0.015,0.020,0.025, \delta=0$ we have:

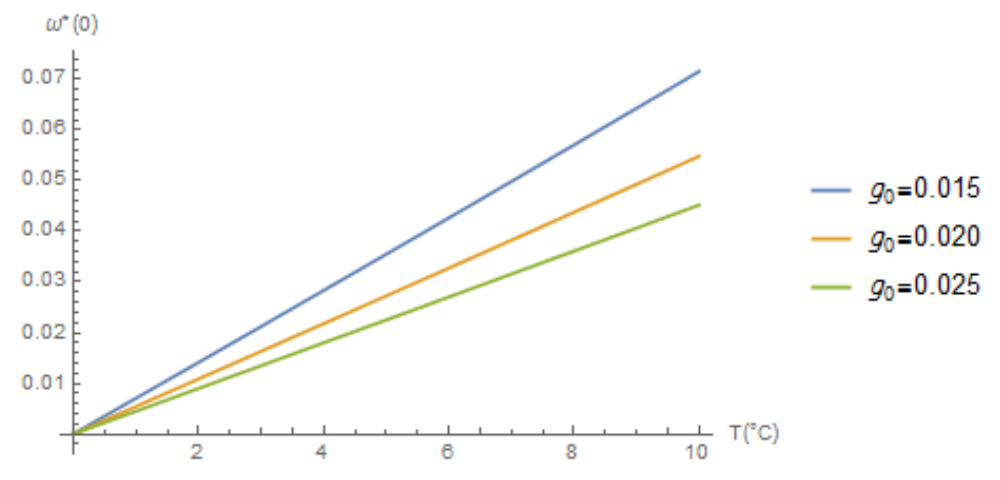

Figure 3.1: W.T.P and temperature change $T_{H}$,the case D.A.R.A and D.R.R.A, $\alpha=-0.3, \beta=-3.55$, $\theta=2.33, g_{0}=0.015,0.020,0.025, \delta=0$.

We have that, the W.T.P remains proportional to temperature increases, such that at the horizon $H$, a greater value of $T_{H}$ would produce a greater willingness to pay; similarly, the W.T.P remains inversely proportional to the initial G.D.P growth rate, $g_{0}$. For $T_{H}=10^{\circ} \mathrm{C}, g_{0}=0.015$, Figure 3.1 tells us that, for the less averse person $w^{*}(0)=7 \%$.

\subsubsection{W.T.P and $T_{H}$ : the case D.A.R.A and I.R.R.A: $0<\alpha<1, \beta>0$.}

This category represents the average risk averse agents, and with parameter values of $\alpha=0.42, \beta=1.2$, $\theta=2.33, g_{0}=0.015,0.020,0.025, \delta=0$ we have:

The W.T.P remains proportional to temperature increases, and inversely proportional to the initial G.D.P growth rate. For $T_{H}=10^{\circ} \mathrm{C}, g_{0}=0.015$, Figure 3.2 tells us that for the averagely less averse person $w^{*}(0)=2 \%$.

\footnotetext{
${ }^{16}$ We keep $\theta$ constant at 2.33 , since the exponential utility function is unique but for an affine transformation, the parameter $\theta$ does not affect the characterization of social utility classes.
} 


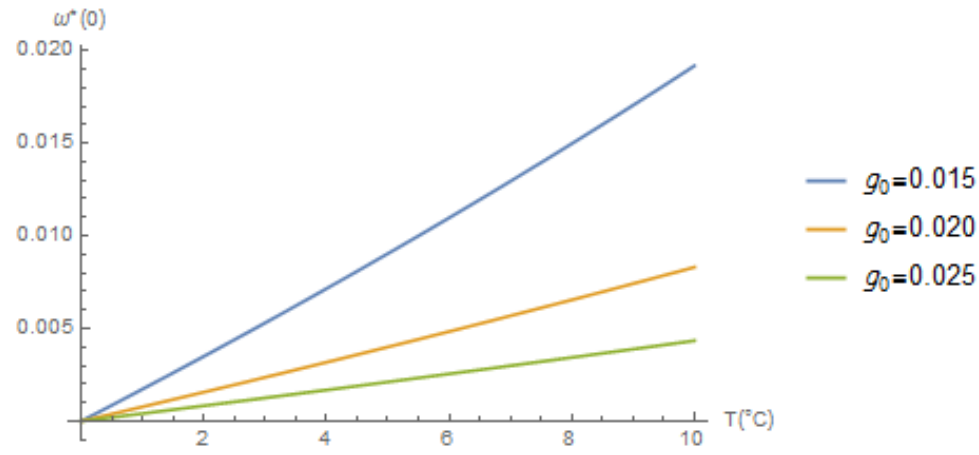

Figure 3.2: W.T.P and temperature change $T_{H}$, the case D.A.R.A and I.R.R.A, $\alpha=0.42, \beta=1.2$, $\theta=2.33, g_{0}=0.015,0.020,0.025, \delta=0$.

\subsubsection{W.T.P and $T_{H}$ : the case C.A.R.A and I.R.R.A: $\alpha=1, \beta>0$.}

This category represents the averagely more risk averse agents, and with parameter values of $\alpha=1$, $\beta=1.2, \theta=2.33, g_{0}=0.015,0.020,0.025, \delta=0$, we have:

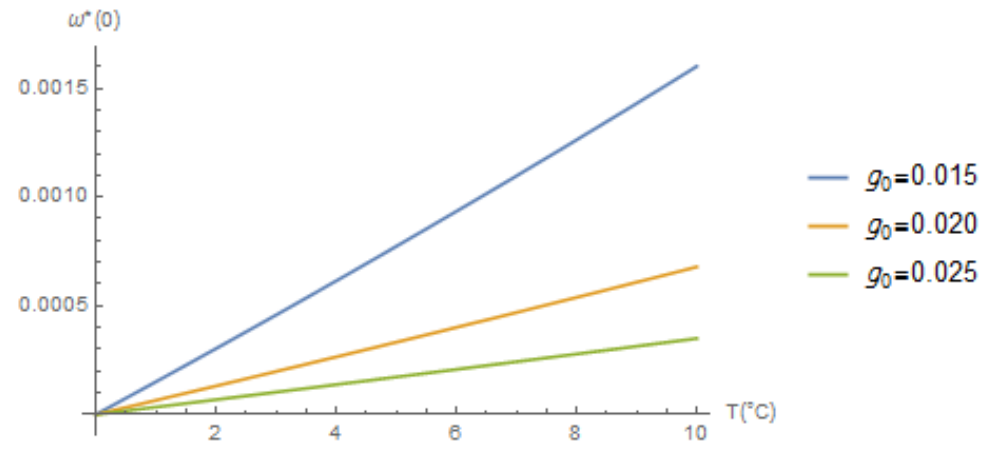

Figure 3.3: W.T.P and temperature change $T_{H}$, the case C.A.R.A and I.R.R.A, $\alpha=1, \beta=1.2, \theta=2.33$ , $g_{0}=0.015,0.020,0.025, \delta=0$.

The W.T.P remains proportional to temperature increases, and inversely proportional to the initial G.D.P growth rate. For $T_{H}=10^{\circ} \mathrm{C}, g_{0}=0.015$, Figure 3.3 tells us that for the averagely more averse individual $w^{*}(0)=0.17 \%$.

\subsubsection{W.T.P and $T_{H}$ : the case I.A.R.A and I.R.R.A: $\alpha>1, \beta>0$.}

This category represents the most risk averse agents, and with parameter values of $\alpha=1.2, \beta=1.2$, $\theta=2.33, g_{0}=0.015,0.020,0.025, \delta=0$, we have that W.T.P remains proportional to temperature increases, and inversely proportional to the initial G.D.P growth rate. For $T_{H}=10^{\circ} \mathrm{C}, g_{0}=0.015$, Figure 3.4 tells us that for the most averse individual $w^{*}(0)=0.09 \%$, and significantly below $1 \%$.

\subsection{Influences on W.T.P: the case of uncertainty.}

In the case of uncertainty, temperature and the economic-impact parameters follow the distributions of Figure 2.1 and Figure 2.2 respectively. Varying the W.T.P for values of $\tau$ at the horizon $H=100$, in the following charts, we have the calculation of $w^{*}(\tau)$, the willingness to pay to keep $T_{H} \leq \tau$, for different values of $\tau$. We vary the parameters $\alpha, \beta, g_{0}$ and $\delta$, and study how these affect the W.T.P. 


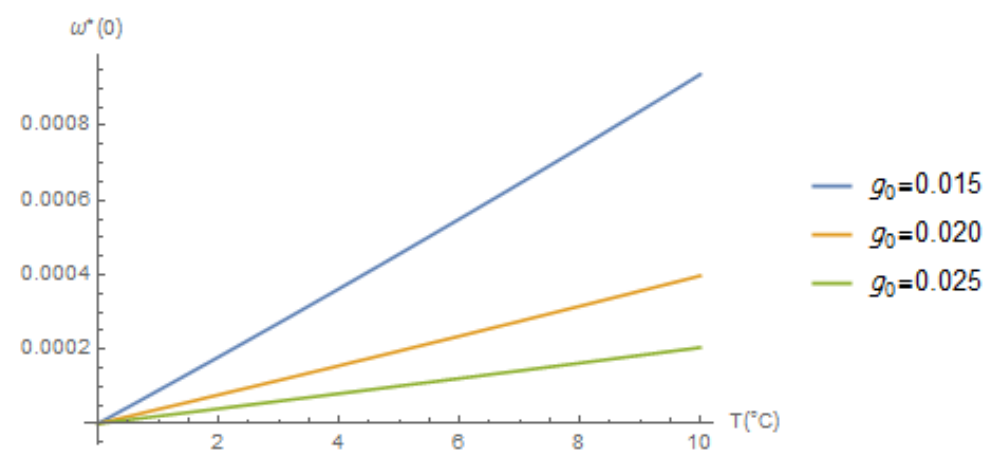

Figure 3.4: W.T.P and temperature change $T_{H}$, the case I.A.R.A and I.R.R.A, $\alpha=1.2, \beta=1.2, \theta=2.33$ , $g_{0}=0.015,0.020,0.025, \delta=0$.

\subsubsection{W.T.P and $\tau$ : the case D.A.R.A and D.R.R.A: $\alpha<0, \beta<0$.}

For parameters values of $\alpha=-0.2,-0.3, \beta=-3.55, \theta=2.33, g_{0}=0.019,0.020,0.021$ and $\delta=0$, we have:

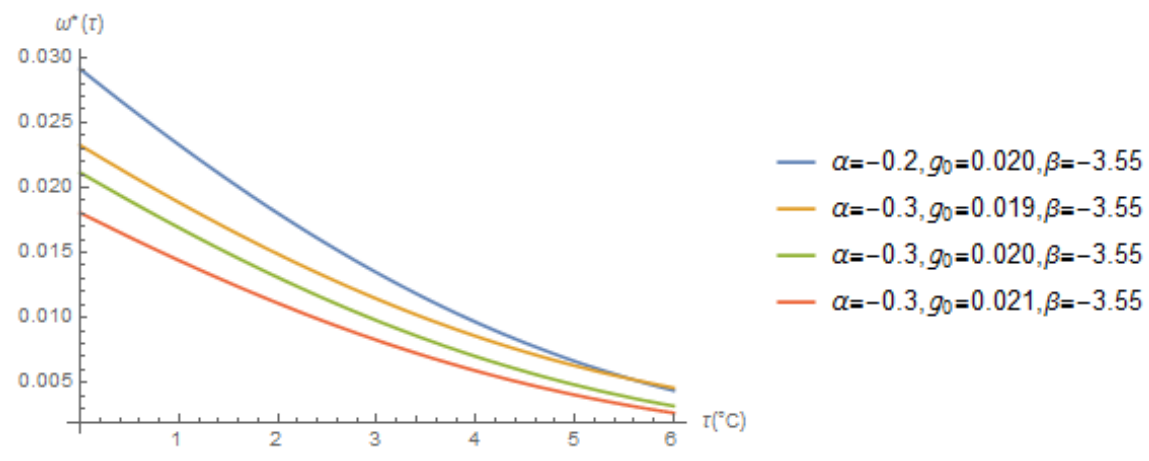

Figure 3.5: W.T.P and $\tau$, the case D.A.R.A and D.R.R.A, $\alpha=-0.2,-0.3, \beta=-3.55, \theta=2.33, g_{0}=0.019$, $0.020,0.021, \delta=0$.

In Figure 3.5, for $\alpha=-0.3, \beta=-3.55$ and $g_{0}=0.019$, we have that the less averse individual would be willing to sacrifice $w^{*}(0)=2.3 \%$. If we take the values of $\alpha=-0.2$ and $g_{0}=0.020$, the value of $w^{*}(0)$ increases to $2.9 \%$. We have that, for agents characterized by a DARA/DRRA utility, the W.T.P is proportional to $\alpha$ and inversely proportional to $g_{0}$ and $\tau$. In fact, for the D.A.R.A/D.R.R.A class, $w^{*}(0)$ is terribly sensitive ${ }^{17}$ to a decrease in $g_{0}$, and if $g_{0}$ falls to $0.018, w^{*}(0)$ increases significantly to $16.4 \%$ in Figure 3.6.

\subsubsection{W.T.P and $\tau$ : the case D.A.R.A and I.R.R.A: $0<\alpha<1, \beta>0$.}

For values of $\alpha=0.35,0.42, \beta=1.2, \theta=2.33, g_{0}=0.019,0.020,0.021$ and $\delta=0$, we have:

In Figure 3.7, with parameter values of $\alpha=0.42, \beta=1.2$ and $g_{0}=0.019, w^{*}(0)=0.3 \%$, and if $\alpha$ is reduced to 0.35 , for $g_{0}=0.020$ and the same value of $\beta, w^{*}(0)$ inceases to $0.44 \%$. We have, in this utility class, that the W.T.P is inversely proportional to $\alpha, \tau$ and $g_{0}$.

\subsubsection{W.T.P and $\tau$ : the case C.A.R.A and I.R.R.A: $\alpha=1, \beta>0$.}

For values of $\alpha=1, \beta=1.2, \theta=2.33, g_{0}=0.019,0.020,0.021$ and $\delta=0$, we have in Figure 3.8, for $g_{0}=0.020$ and $\beta=1.2$, that $w^{*}(0)=0.025 \%$. Since $\alpha$ is constant in this case, to know how the W.T.P

\footnotetext{
${ }^{17}$ if for example $g_{0}$ decreases to $15 \%$ we have values of $w^{*}(0)$ close to $100 \%$, which doesn't translate into a climate policy, reason why we took the initial value of $g_{0}$ at 0.019 , which is very close to its expected value of 0.020 .
} 


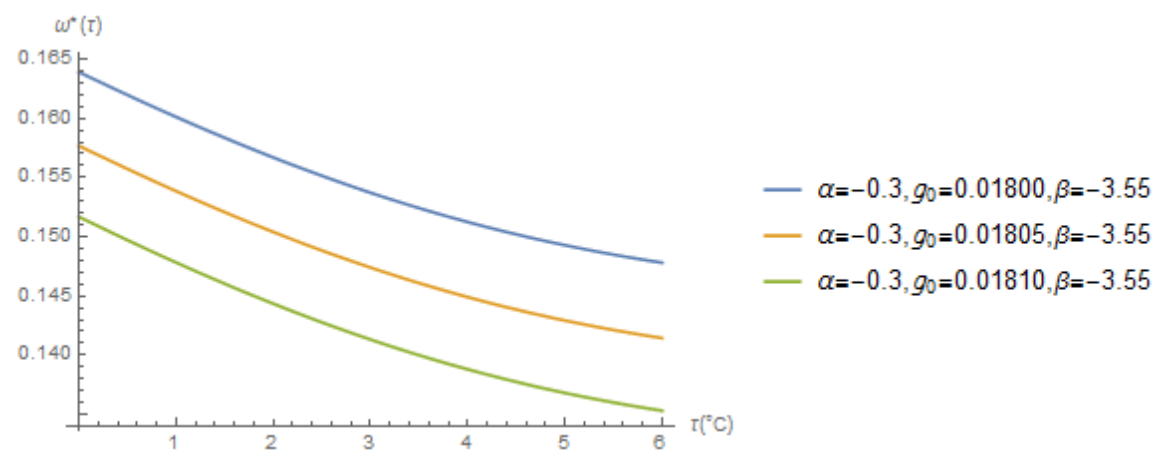

Figure 3.6: W.T.P and $\tau$, the case D.A.R.A and D.R.R.A, $\alpha=-0.3, \beta=-3.55, \theta=2.33, g_{0}=0.01801$, $0.01802,0.01803, \delta=0$.

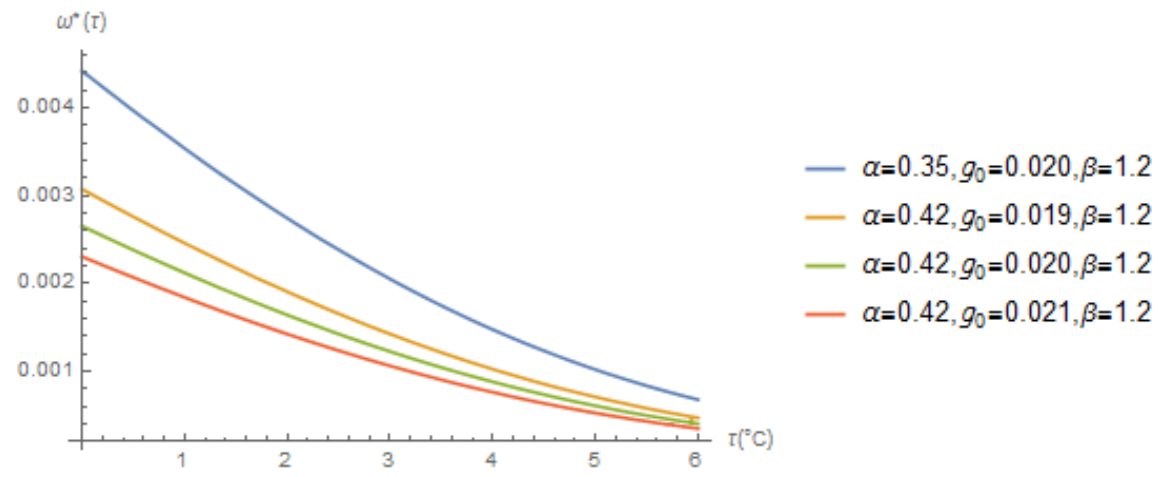

Figure 3.7: W.T.P and $\tau$, the case D.A.R.A and I.R.R.A, $\alpha=0.35,0.42, \beta=1.2, \theta=2.33, g_{0}=0.019$, $0.020,0.021, \delta=0$.

behaves with respect to increases in $\alpha$, we shall see, in the next figure, how for $\alpha>1$, the W.T.P decreases; So the W.T.P remains inversely proportional to $\alpha, \tau$ and $g_{0}$. For the variation with respect to $\beta$, we shall see later that W.T.P is also inversely proportional to $\beta$.

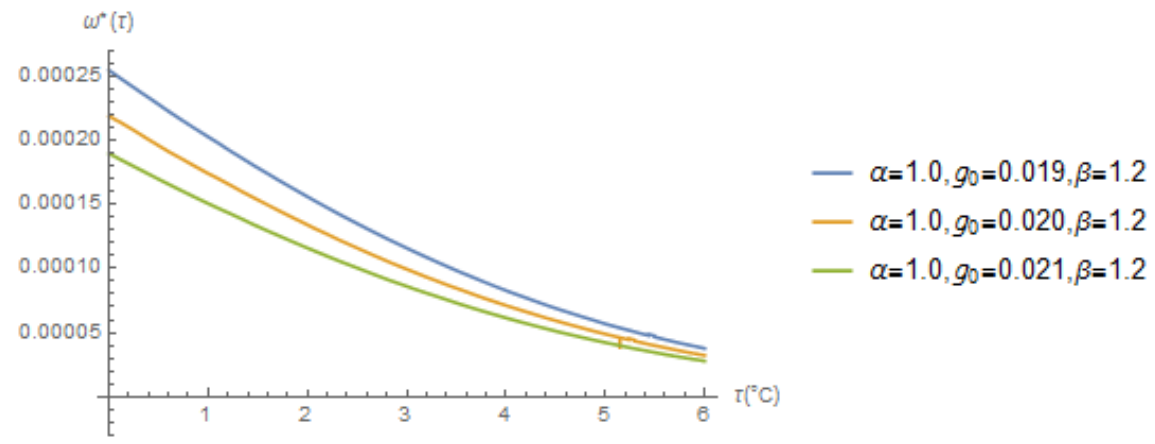

Figure 3.8: W.T.P and $\tau$,the case C.A.R.A and I.R.R.A, $\alpha=1, \beta=1.2, \theta=2.33, g_{0}=0.019,0.020$, $0.021, \delta=0$.

\subsubsection{W.T.P and $\tau$ : the case I.A.R.A and I.R.R.A: $\alpha>1, \beta>0$.}

In this case, we progressively fall into the most averse utility class, IARA/IRRA; and we get the lowest values of W.T.P. For values of $\alpha=1.07,1.2, \beta=1.2, \theta=2.33, g_{0}=0.019,0.020,0.021$ and $\delta=0$, we have: 


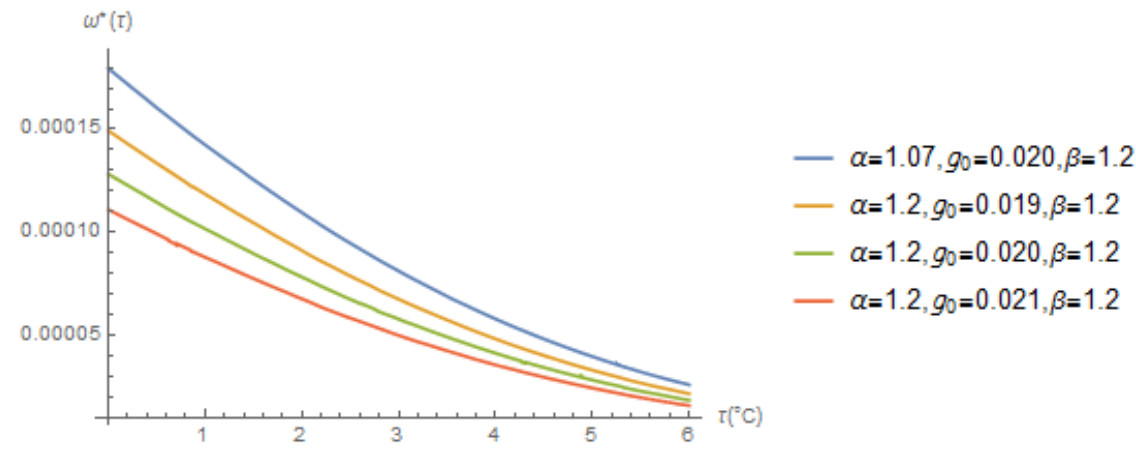

Figure 3.9: W.T.P and $\tau$, the case I.A.R.A and I.R.R.A, $\alpha=1.07,1.2, \beta=1.2, \theta=2.33, g_{0}=0.019$, $0.020,0.021, \delta=0$.

and we see in Figure 3.9 that if $\alpha$ is reduced from 1.2 to 1.07 , with the same value of $\beta, w^{*}(0)$ increases from $0.015 \%$ to $0.018 \%$. We therefore have in this case as seen above, that the W.T.P is inversely proportional to $\alpha, \tau$ and $g_{0}$.

\subsubsection{W.T.P and $\alpha: \mathcal{E}(T)=3$ and 5: the case D.A.R.A and D.R.R.A: $\alpha<0, \beta<0$.}

For the DARA/DRRA class, with $\mathcal{E}(T)=3$, the least averse class (if not at all), we get values of $w^{*}(3)$ close to a $100 \%$ for values of $\alpha<-0.35$, for $\delta=0.01(\alpha<-0.33$, for $\delta=0$.).
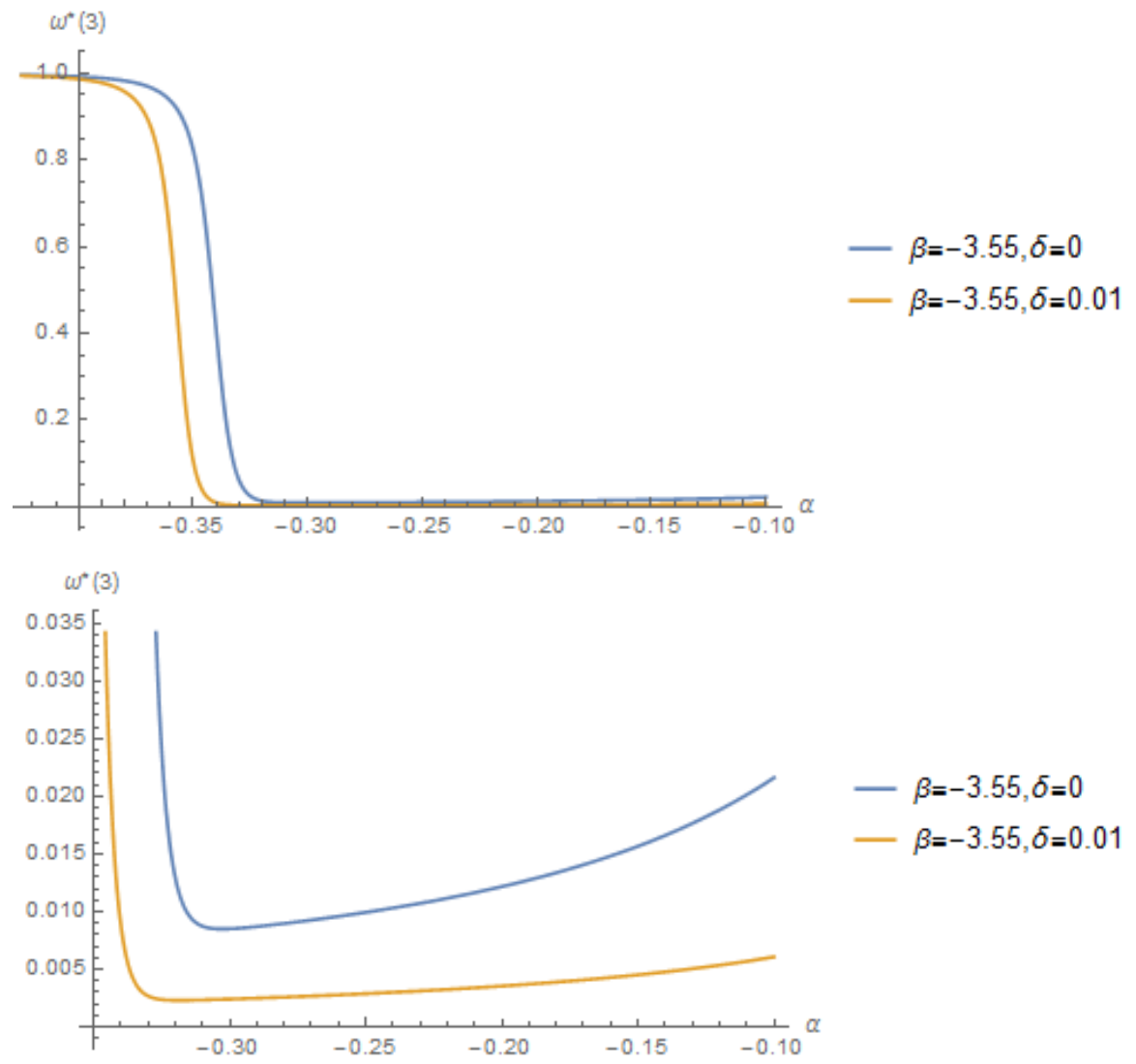

Figure 3.10: W.T.P and $\tau=3$, the case D.A.R.A and D.R.R.A, $\beta=-3.55, \theta=2.33, g_{0}=0.020, \delta=0$, 0.01 .

Above, in the DARA/DRRA frame, we said that the W.T.P is directly proportional to $\alpha$, but this 
is not always the case. In fact, for some small values of $\alpha$, the W.T.P is inversely proportional, and then there is bifurcation, and the W.T.P becomes directly proportional. In Figure 3.10, for a variation of values of $\alpha$, with $\beta$ constant at $-3.55, g_{0}=0.020$, for $\delta=0$, the W.T.P is inversely proportional to $\alpha$ until $\alpha=-0.31$, then proportional thereafter (for $\delta=0.01$, until $\alpha=-0.33$, then proportional thereafter).

Moreover, for the case DARA/DRRA, just as in the C.R.R.A frame, an increase in the utility discount rate, $\delta$, would reduce the W.T.P; we will see that this is not always the case for other utility classes.

If we increase $\mathcal{E}(T)$ to 5 , with the same parameter values, we can see in Figure 3.11 that the two curves of $w^{*}(3)$ have risen; from $3.4 \%$ to $6.4 \%$ for $\delta=0.01, \alpha$ around -0.34 (for $\delta=0, \alpha$ around -0.325 ). We see that an increase of $\mathcal{E}(T)$ leads to an increase of $w^{*}(3)$.

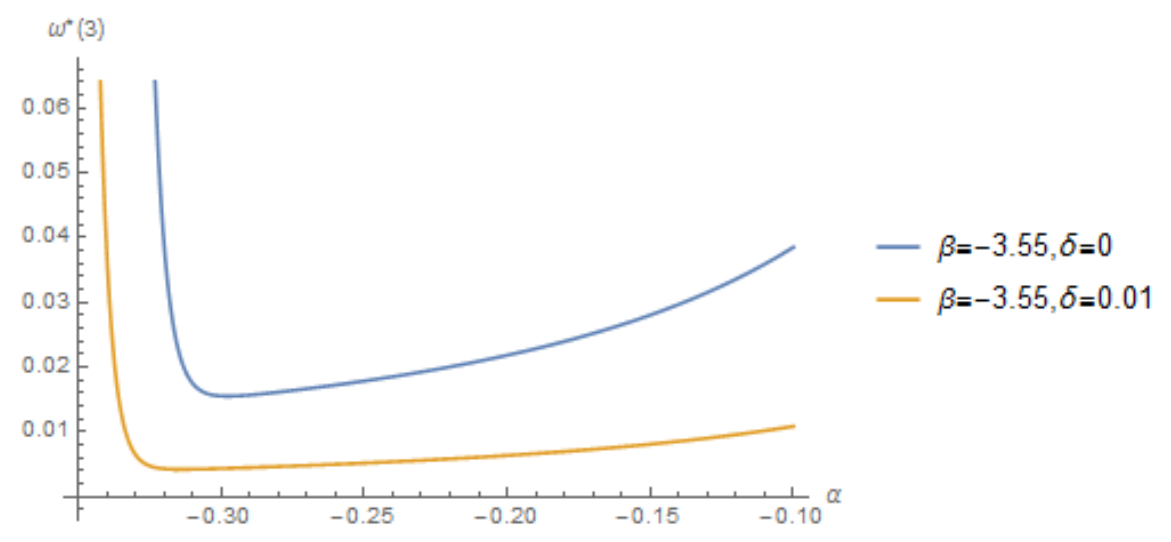

Figure 3.11: W.T.P and $\tau=3$, the case D.A.R.A and D.R.R.A, $\mathcal{E}(T)=5, \beta=-3.55, \theta=2.33, g_{0}=0.020$, $\delta=0,0.01$.

\subsubsection{W.T.P and $\alpha: \mathcal{E}(T)=3$ and 5: the case D.A.R.A and I.R.R.A: $0<\alpha<1, \beta>0$.}

For the case DARA/IRRA, with $\mathcal{E}(T)=3$, the averagely least averse class, we obtain values of $w^{*}(3)$ around $1 \%$. For values of $\alpha$ in $(0,1)$, with $\beta$ constant at $1.2, g_{0}=0.020, \delta=0$ and 0.01 , we have:

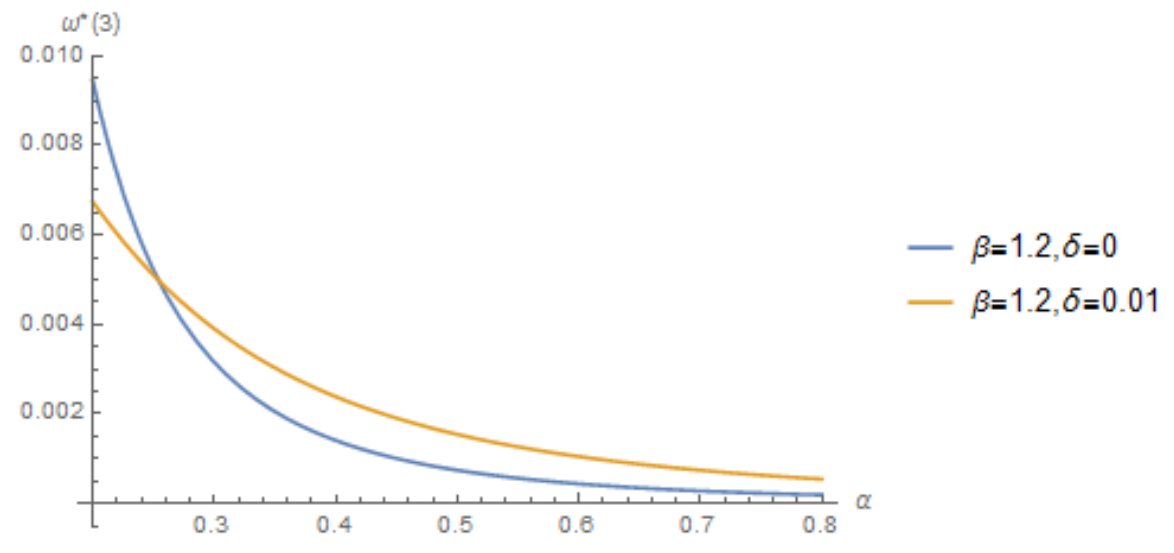

Figure 3.12: W.T.P and $\tau=3$, the case D.A.R.A and I.R.R.A, $\beta=1.2, \theta=2.33, g_{0}=0.020, \delta=0,0.01$.

Unlike the case DARA/DRRA, here, the W.T.P is always inversely proportional to alpha and an increased utility discount rate, $\delta$, can either increase or decrease the W.T.P; in Figure 3.12, although 


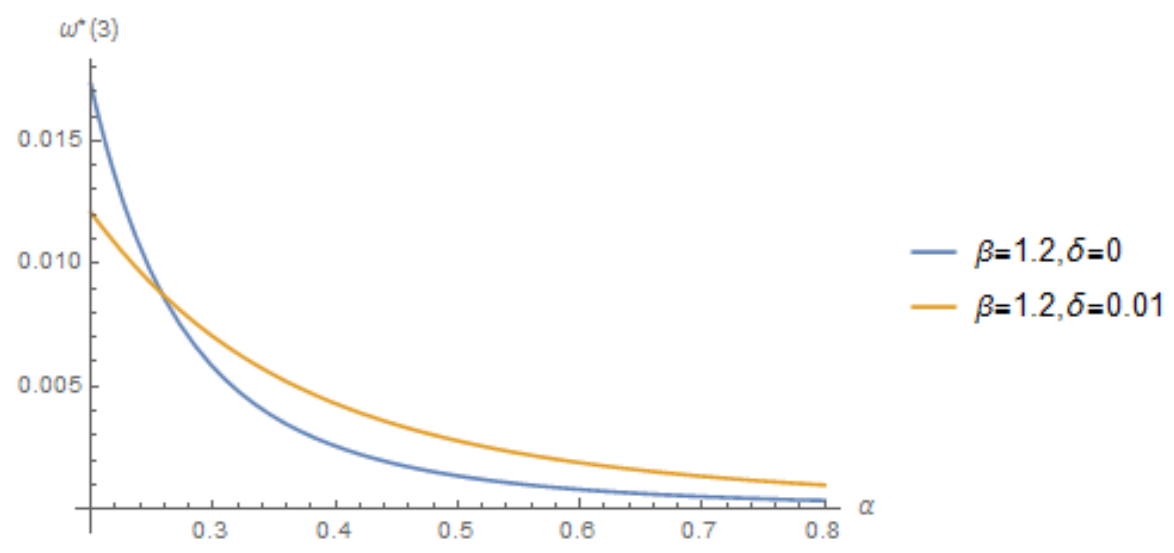

Figure 3.13: W.T.P and $\tau=3$, the case D.A.R.A and I.R.R.A, $\mathcal{E}(T)=5, \beta=1.2, \theta=2.33, g_{0}=0.020$, $\delta=0,0.01$.

$\delta$ is increased from 0 to 0.01 , for $\alpha<0.26, w^{*}(3)$ is decreased, and for $\alpha>0.26, w^{*}(3)$ is increased.

If we increase $\mathcal{E}(T)$ to 5 , in Figure 3.13 , with the same parameter values, we see that $w^{*}(3)$ is proportional to $\mathcal{E}(T)$.

\subsubsection{W.T.P and $\alpha: \mathcal{E}(T)=3$ and 5: the case C.A.R.A and I.R.R.A: $\alpha=1, \beta>0$.}

For the CARA/IRRA frame, with $\mathcal{E}(T)=3$, the averagely more averse class, $\alpha$ is constant at 1 and $\beta$ varies for positive values. For $\beta$ varying in $[0.2,1.2], g_{0}=0.020, \delta=0$ et 0.01 , we have:

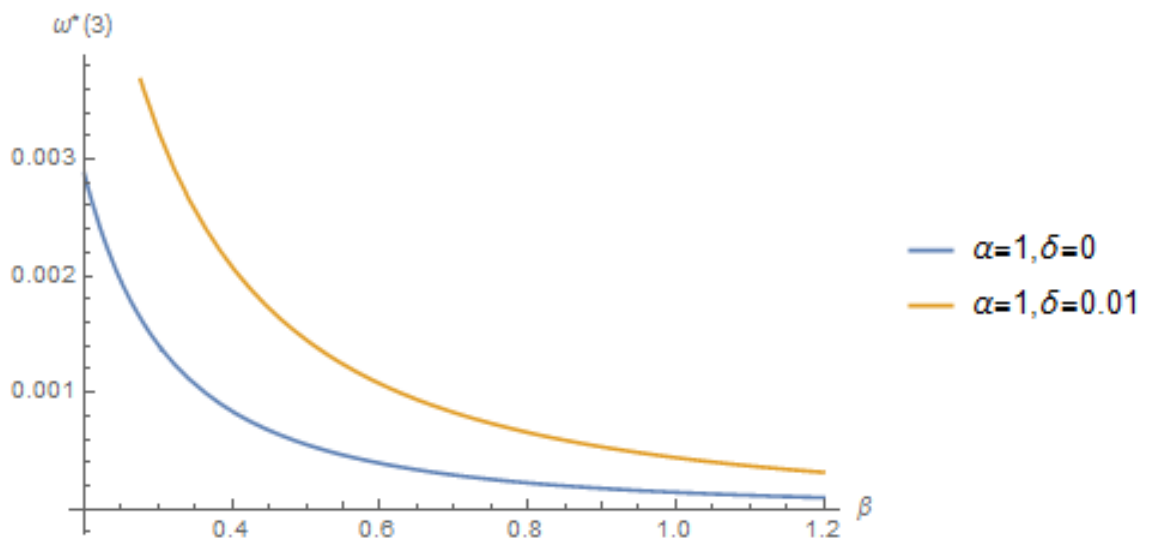

Figure 3.14: W.T.P and $\tau=3$, the case C.A.R.A and I.R.R.A, $\alpha=1, \theta=2.33, g_{0}=0.020, \delta=0,0.01$.

We find that the W.T.P is inversely proportional to $\beta$ but directly proportional to $\delta$ because in Figure 3.14 , an increase in the utility discount rate, $\delta$, increases the W.T.P .

If we increase $\mathcal{E}(T)$ to 5 , with the same parameter values, we have: and likewise, we see that $w^{*}(3)$ is proportional to $\mathcal{E}(T)$.

3.4.8 W.T.P and $\alpha: \mathcal{E}(T)=3$ and 5: the case I.A.R.A and I.R.R.A: $\alpha>1, \beta>0$.

When we take values of $\alpha>1$, for $\beta$ positive, we fall into the most averse utility class, IARA/IRRA, and we get the least values of $w^{*}(3)$. For $\alpha$ varying in $[1.001,1.8], g_{0}=0.020, \delta=0$ et 0.01 , we get: 


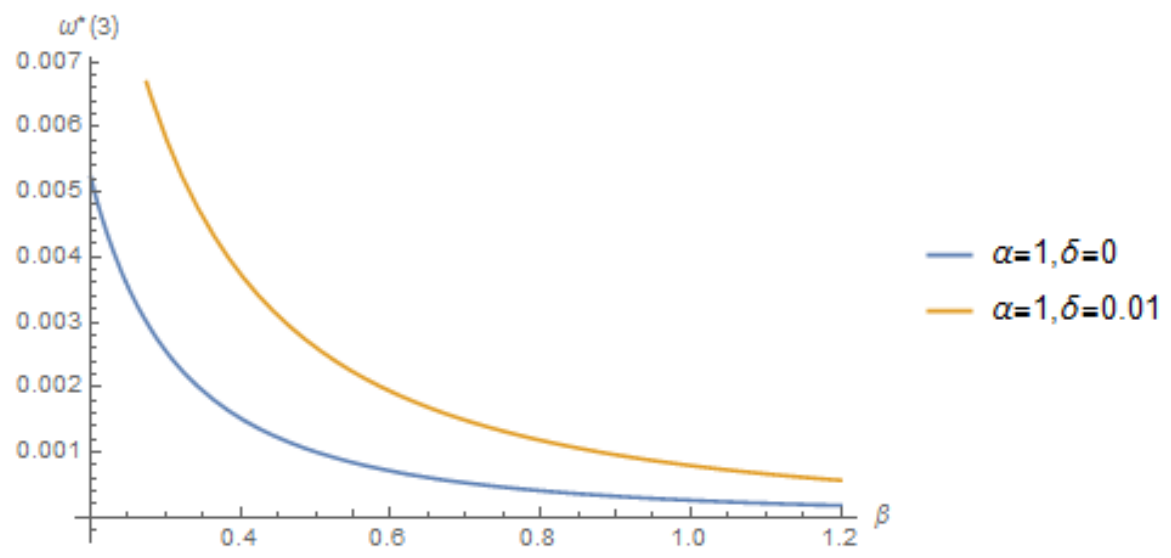

Figure 3.15: W.T.P and $\tau=3$, the case C.A.R.A and I.R.R.A, $\mathcal{E}(T)=5, \alpha=1, \theta=2.33, g_{0}=0.020, \delta=0$, 0.01 .

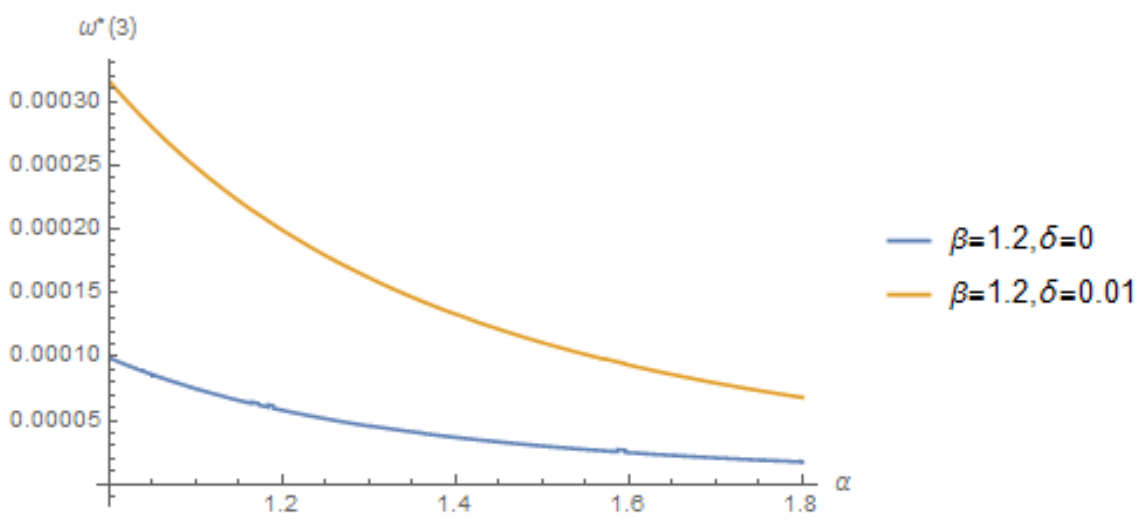

Figure 3.16: W.T.P and $\tau=3$, the case I.A.R.A and I.R.R.A, $\beta=1.2, \theta=2.33, g_{0}=0.020, \delta=0,0.01$.

For this case we find that W.T.P is inversely proportional to $\alpha$, and like before, directly proportional to $\delta$ because in Figure 3.16, an increase of the utility discount rate, $\delta$, increases W.T.P .

If we increase ${ }^{18} \mathcal{E}(T)$ to 5 with the same parameter values, we get that $w^{*}(3)$ is proportional to $\mathcal{E}(T)$.

\subsubsection{W.T.P, $\mathcal{E}(T)$ and $S D(T)$.}

In order to discover between certain and uncertain events, which affect the most the W.T.P for each subclass, in what follows, we calculate the W.T.P for changes in expectation and standard deviation of temperature ${ }^{19}$; expectation, which is our grasp of certainty, and the standard deviation, of uncertainty, will vary one in turn (holding the other constant each time), and we shall observe the W.T.P produced. We shall also calculate, for the same value of W.T.P, the corresponding expectation/standard-deviation couple; as well, we shall calculate the sensitivity of the W.T.P with respect to changes in $\mathcal{E}(T)$ and $S D(T)\left(\partial w^{*} / \partial \mathcal{E}(T)\right.$ and $\left.\partial w^{*} / \partial S D\right)$. For all these different cases, we shall calculate the marginal rate of substitution ${ }^{20}$, M.R.S, between expectation/standard-deviation, treating expectation and standard-deviation as economic goods, and we would finally be able to decide which of the two influences the most the W.T.P of economic agents.

\footnotetext{
${ }^{18}$ Why increase the expectation value?: Because a recent study like Sokolov et al. [18], suggests expected temperature values around $4-5^{\circ} \mathrm{C}$ at the horizon 2100 .

${ }^{19}$ The parameter for economic impact held constant at its expected value of 0.0001363 , as in Pindyck [1] .

${ }^{20}$ M.R.S $=-\left(\partial w^{*} / \partial S D\right) /\left(\partial w^{*} / \partial \mathcal{E}(T)\right)$.
} 


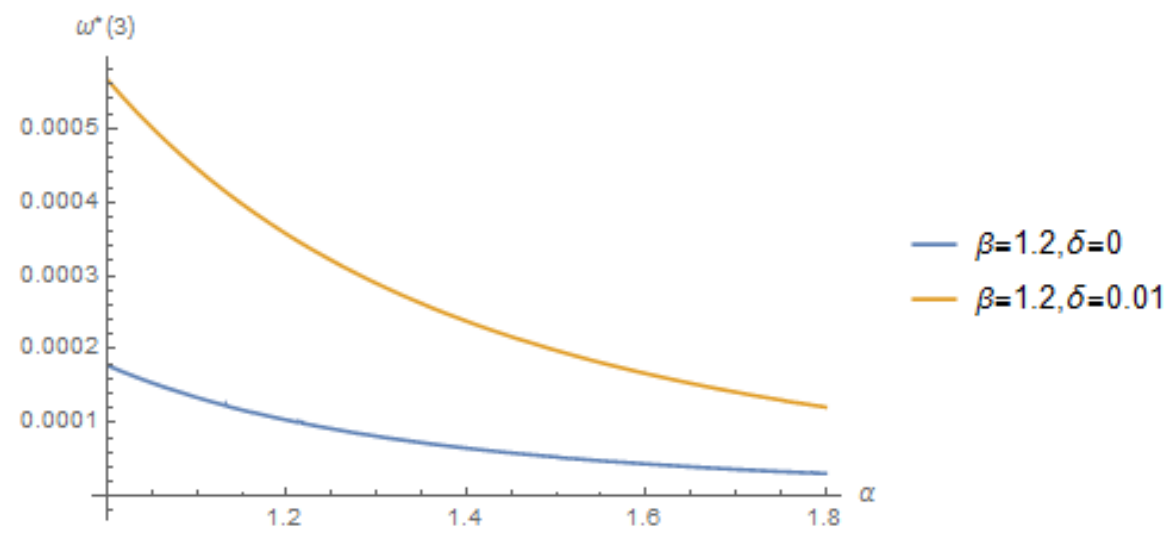

Figure 3.17: W.T.P and $\tau=3$, the case I.A.R.A and I.R.R.A, $\mathcal{E}(T)=5, \beta=1.2, \theta=2.33, g_{0}=0.020$, $\delta=0,0.01$.

\subsubsection{W.T.P, $\mathcal{E}(T)$ and $S D(T): \mathcal{E}(T)=\mathbf{3}$ and 4 : the case D.A.R.A and D.R.R.A: $\alpha<0$, $\beta<0$.}

For values of $\mathcal{E}(T)=3, \alpha=-0.3, \beta=-3.55, \theta=2.33, g_{0}=0.020$ et $\delta=0$, we are in the DARA/DRRA class. In Table 3.2 , we calculate $w^{*}(0)$ (the willingness to pay to prevent any increase of temperature) for changes in the mean and standard-deviation of temperature distribution. In the first part, the standard deviation is maintained at 2.12 and the mean varies, then it is the mean that is held constant at 3.0 and the standard deviation varies; finally, the third part shows combinations of mean and standard deviation which produce the same W.T.P of 0.0179 .

\begin{tabular}{cccccc}
\hline $\mathcal{E}(T)$ & $S D(T)$ & $w^{*}(0)$ & $\partial w^{*} / \partial \mathcal{E}(T)$ & $\partial w^{*} / \partial S D$ & $M . R . S$ \\
\hline $1.2^{\circ} \mathrm{C}$ & $2.12^{\circ} \mathrm{C}$ & 0.0032 & 0.0018 & 0.0070 & -2.20 \\
$\mathbf{3 . 0}^{\circ} \mathrm{C}$ & $\mathbf{2 . 1 2}{ }^{\circ} \mathrm{C}$ & $\mathbf{0 . 0 1 7 9}$ & $\mathbf{0 . 0 0 3 8}$ & $\mathbf{0 . 0 0 8 1}$ & $\mathbf{- 2 . 1 3}$ \\
$4.8^{\circ} \mathrm{C}$ & $2.12^{\circ} \mathrm{C}$ & 0.0257 & 0.0045 & 0.0088 & -1.97 \\
$6.6^{\circ} \mathrm{C}$ & $2.12^{\circ} \mathrm{C}$ & 0.0342 & 0.0050 & 0.0089 & -1.76 \\
& & & & & \\
$3.0^{\circ} \mathrm{C}$ & $1.53^{\circ} \mathrm{C}$ & 0.0107 & 0.0021 & 0.0172 & -7.91 \\
$\mathbf{3 . 0}^{\circ} \mathrm{C}$ & $\mathbf{2 . 1 2}$ & $\mathbf{0 . 0 1 7 9}$ & $\mathbf{0 . 0 0 3 8}$ & $\mathbf{0 . 0 0 8 1}$ & $\mathbf{- 2 . 1 3}$ \\
$3.0^{\circ} \mathrm{C}$ & $3.5^{\circ} \mathrm{C}$ & 0.0259 & 0.0043 & 0.0060 & -1.39 \\
$3.0^{\circ} \mathrm{C}$ & $4.5^{\circ} \mathrm{C}$ & 0.0305 & 0.0064 & 0.0190 & -2.94 \\
& & & & & \\
$4.2^{\circ} \mathrm{C}$ & $1.7^{\circ} \mathrm{C}$ & 0.0179 & 0.0036 & 0.0166 & -4.53 \\
$\mathbf{3 . 0} \mathrm{C}$ & $\mathbf{2 . 1 2}$ & $\mathbf{0 . 0 1 7 9}$ & $\mathbf{0 . 0 0 3 8}$ & $\mathbf{0 . 0 0 8 1}$ & $\mathbf{- 2 . 1 3}$ \\
$1.0^{\circ} \mathrm{C}$ & $3.45^{\circ} \mathrm{C}$ & 0.0179 & 0.0033 & 0.0022 & -0.66 \\
$0.2^{\circ} \mathrm{C}$ & $3.45^{\circ} \mathrm{C}$ & 0.0179 & 0.0046 & 0.0036 & -0.78 \\
$0.11^{\circ} \mathrm{C}$ & $4.12^{\circ} \mathrm{C}$ & 0.0179 & 0.0048 & 0.0180 & -3.73 \\
$4.922^{\circ} \mathrm{C}$ & $1.554^{\circ} \mathrm{C}$ & 0.0179 & 0.0041 & 0.0240 & -5.81 \\
\hline
\end{tabular}

Table 3.2: W.T.P, changes in $\mathcal{E}(T)$ and $S D(T) . \quad \gamma=\mathcal{E}(\gamma)=0.0001363, \mathcal{E}(T)=3 . \quad \alpha=-0.3, \beta=-3.55$, $\theta=2.33, g_{0}=0.020$ and $\delta=0$.

Apart from extreme values of $\mathcal{E}(T)$ and $S D(T), \partial w^{*} / \partial \mathcal{E}(T)$ is contained in the range 0.0018-0.0064 and $\partial w^{*} / \partial S D$ in 0.0022-0.0240, in such a way that the M.R.S lies between -1 and -3.75 . We can see that the M.R.S oscillates between small and large values; in Figure 3.18 from -5.81 for $(1.55,4.92)$ 
to -2.13 for $(2.12,3.0)$ and -3.73 for $(4.12,0.11)^{21}$, incrementing the expectation of the temperature distribution to $4.0^{\circ} \mathrm{C}$, we have the iso-W.T.P curves in Figure 3.18 and we can see how the W.T.P is directly proportional to changes in the mean. The fact that the M.R.S is large in absolute value for small values of standard deviation shows us how major changes in the mean are equivalent in terms of welfare, to small changes in the standard deviation (The average doubles from 2.5 to 5 , the standard deviation reduces only by 0.8 but still producing the same W.T.P of 0.0179). The top curve shows combinations of mean and standard deviation for which the W.T.P is 0.0221 , this value of the W.T.P results in keeping the standard deviation at $2.12^{\circ} \mathrm{C}$, but incrementing the mean to $4^{\circ} \mathrm{C}$.

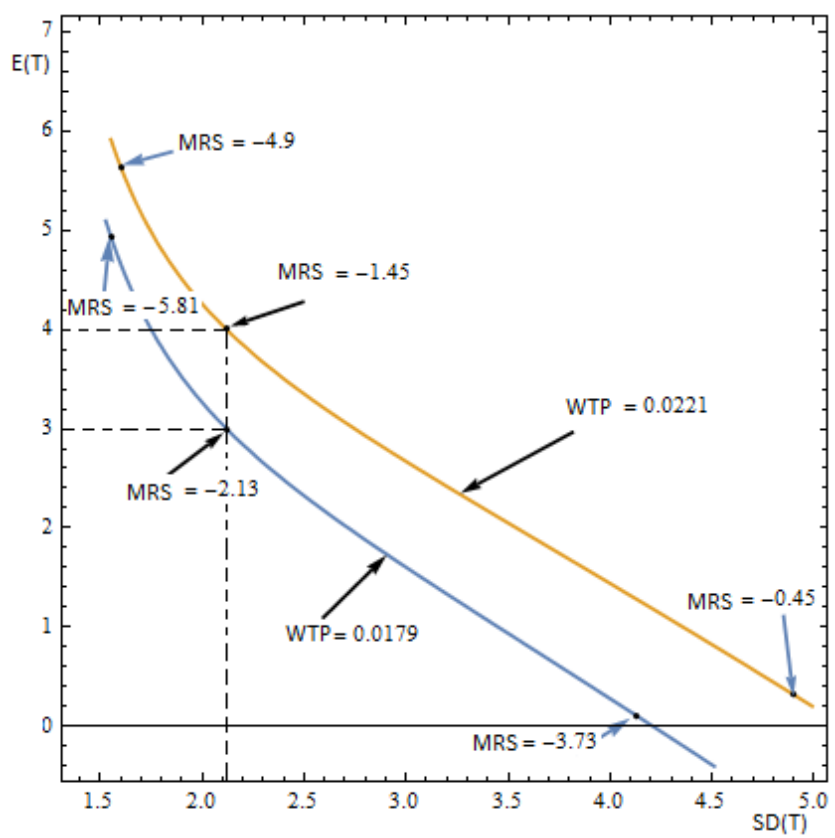

Figure 3.18: Iso-W.T.P curves, $w^{*}(0)=0.0179(\mathcal{E}(T)=3)$ and $w^{*}(0)=0.0221\left(\mathcal{E}(T)=4.0^{\circ} \mathrm{C}\right) ; \alpha=-0.3$, $\beta=-3.55, \theta=2.33, g_{0}=0.020$ and $\delta=0$.

3.4.11 W.T.P, $\mathcal{E}(T)$ and $S D(T): \mathcal{E}(T)=3$ : the case D.A.R.A and I.R.R.A: $0<\alpha<1$, $\beta>0$.

We have, for $\mathcal{E}(T)=3$ and parameter values of $\alpha=0.42, \beta=1.2, \theta=2.33, g_{0}=0.020$ and $\delta=0$, as before in Table 3.3 results for the DARA/IRRA class. $\partial w^{*} / \partial \mathcal{E}(T)$ lies within $0.0008-0.0134$ and $\partial w^{*} / \partial S D$ within 0.0002-0.0603, in such a way that the M.R.S should lie within -0.3 and -5 . We can notice that the M.R.S oscillates between small and large values; in Figure 3.19 from -16.81 for $(1.54,4.78)$ to -2.27 for $(2.12,3.0)$ and -12.27 for $(3.81,0.67)$.

The fact that the M.R.S is large in absolute value for small values of the standard deviation shows us how major changes in the mean are equivalent, in terms of welfare, to small changes in the standard deviation (The mean doubles from 2.5 to 5 , the standard deviation reduces only by 1.5 but producing the same W.T.P of 0.0027). We have the corresponding iso-W.T.P curve,

3.4.12 W.T.P: $\mathcal{E}(T)$ and $S D(T): \mathcal{E}(T)=$ 3: the case C.A.R.A and I.R.R.A: $\alpha=1, \beta>0$.

For parameter values of $\alpha=1, \beta=1.2, \theta=2.33, g_{0}=0.020$ and $\delta=0$, we are in the CARA/IRRA class. In Table 3.4, $\partial w^{*} / \partial \mathcal{E}(T)$ lies within -0.0165-0.0055 and $\partial w^{*} / \partial S D$ within -0.0876-0.0087, in such

\footnotetext{
${ }^{21}$ for $T=4.0^{\circ} \mathrm{C}$, from -4.9 for $(1.628,5.511)$ to -1.45 for $(2.12,3.0)$ and -0.45 for $(4.839,0.327)$.
} 


\begin{tabular}{cccccc}
\hline $\mathcal{E}(T)$ & $S D(T)$ & $w^{*}(0)$ & $\partial w^{*} / \partial \mathcal{E}(T)$ & $\partial w^{*} / \partial S D$ & $M . R . S$ \\
\hline $1.2^{\circ} \mathrm{C}$ & $2.12^{\circ} \mathrm{C}$ & 0.0018 & 0.0026 & 0.0017 & -0.67 \\
$\mathbf{3 . 0}^{\circ} \mathrm{C}$ & $\mathbf{2 . 1 2}^{\circ} \mathrm{C}$ & $\mathbf{0 . 0 0 2 7}$ & $\mathbf{0 . 0 0 1 1}$ & $\mathbf{0 . 0 0 2 6}$ & $\mathbf{- 2 . 2 7}$ \\
$5.2^{\circ} \mathrm{C}$ & $2.12^{\circ} \mathrm{C}$ & 0.0042 & 0.0017 & 0.0020 & -1.15 \\
$5.8^{\circ} \mathrm{C}$ & $2.12^{\circ} \mathrm{C}$ & 0.0046 & 0.0023 & 0.0023 & -1 \\
& & & & & \\
$3.0^{\circ} \mathrm{C}$ & $1.53^{\circ} \mathrm{C}$ & 0.0018 & 0.0134 & 0.0108 & -0.81 \\
$\mathbf{3 . 0}^{\circ} \mathrm{C}$ & $\mathbf{2 . 1 2}^{\circ} \mathrm{C}$ & $\mathbf{0 . 0 0 2 7}$ & $\mathbf{0 . 0 0 1 1}$ & $\mathbf{0 . 0 0 2 6}$ & $\mathbf{- 2 . 2 7}$ \\
$3.0^{\circ} \mathrm{C}$ & $2.117^{\circ} \mathrm{C}$ & 0.0027 & 0.0011 & 0.0037 & -3.30 \\
& & & & & \\
$4.78^{\circ} \mathrm{C}$ & $1.54^{\circ} \mathrm{C}$ & 0.0027 & 0.0008 & 0.0145 & -16.58 \\
$4.8^{\circ} \mathrm{C}$ & $1.53^{\circ} \mathrm{C}$ & 0.0027 & 0.0019 & 0.0002 & -0.14 \\
$4.2^{\circ} \mathrm{C}$ & $1.66^{\circ} \mathrm{C}$ & 0.0027 & 0.0008 & 0.0037 & -4.22 \\
$\mathbf{3 . 0}^{\circ} \mathrm{C}$ & $\mathbf{2 . 1 2}^{\circ} \mathrm{C}$ & $\mathbf{0 . 0 0 2 7}$ & $\mathbf{0 . 0 0 1 1}$ & $\mathbf{0 . 0 0 2 6}$ & $\mathbf{- 2 . 2 7}$ \\
$0.6^{\circ} \mathrm{C}$ & $3.85^{\circ} \mathrm{C}$ & 0.0027 & 0.0064 & 0.0414 & -6.46 \\
$0.67^{\circ} \mathrm{C}$ & $3.81^{\circ} \mathrm{C}$ & 0.0027 & 0.0049 & 0.0603 & -12.27 \\
\hline
\end{tabular}

Table 3.3: W.T.P, changes in $\mathcal{E}(T)$ and $S D(T) . \quad \gamma=\mathcal{E}(\gamma)=0.0001363, \mathcal{E}(T)=3 . \quad \alpha=0.42, \quad \beta=1.2$, $\theta=2.33, g_{0}=0.020$ and $\delta=0$.

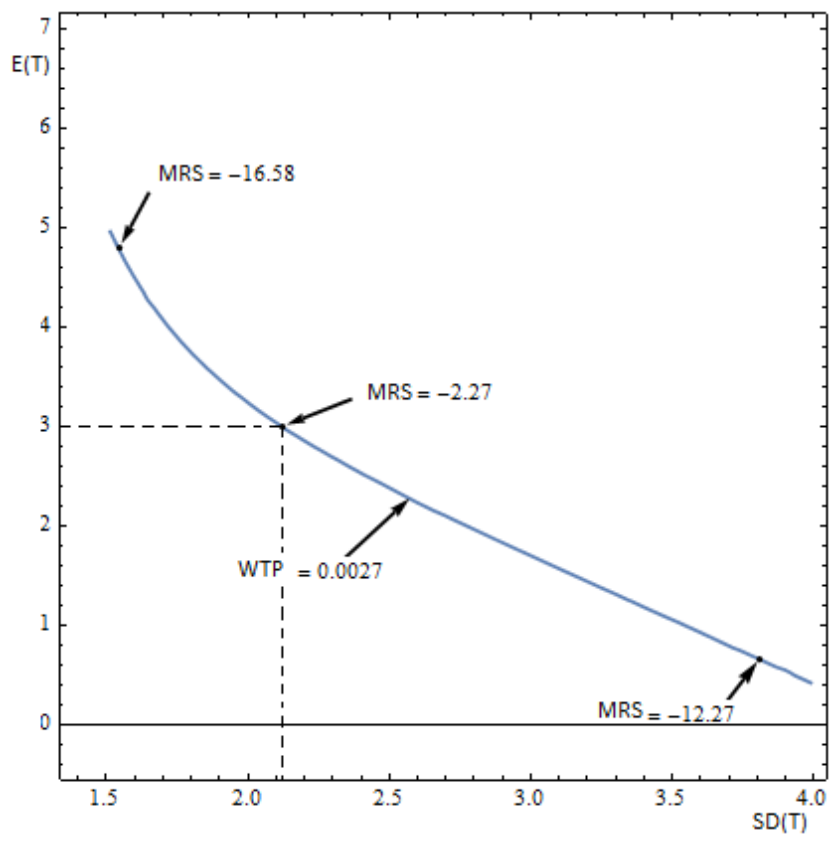

Figure 3.19: Iso-W.T.P curve, $w^{*}(0)=0.0027\left(\mathcal{E}(T)=3.0^{\circ} \mathrm{C}\right) ; \alpha=0.42, \beta=1.2, \theta=2.33, g_{0}=0.020$ and $\delta=0$.

a way that the M.R.S is within -5 and -2 . We can see that the M.R.S oscillates between low and high values; in Figure 3.20 from -2.44 for $(1.54,4.122)$ to -0.57 for $(2.12,3.0)$ and -0.34 for $(2.9214,2.0)$.

Similarly as before, we have larger (in absolute value) M.R.S values for small standard deviation values. 


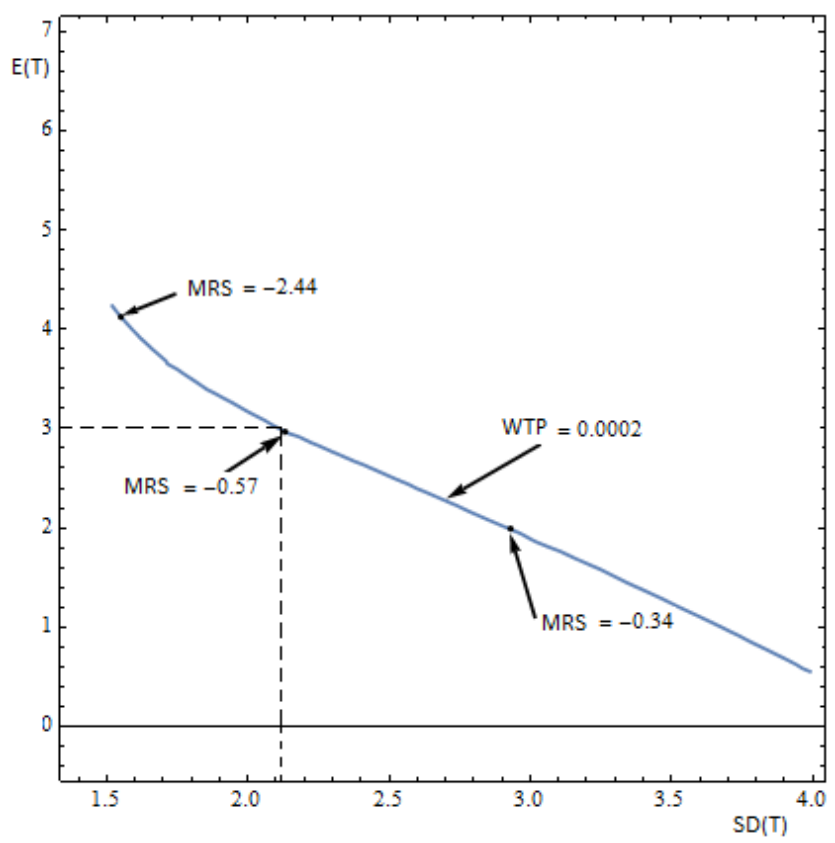

Figure 3.20: Iso-W.T.P curve, $w^{*}(0)=0.0002\left(\mathcal{E}(T)=3.0^{\circ} \mathrm{C}\right) ; \alpha=1, \beta=1.2, \theta=2.33, g_{0}=0.020$ and $\delta=0$.

\begin{tabular}{cccccc}
\hline $\mathcal{E}(T)$ & $S D(T)$ & $w^{*}(0)$ & $\partial w^{*} / \partial \mathcal{E}(T)$ & $\partial w^{*} / \partial S D$ & $M . R . S$ \\
\hline $1.2^{\circ} \mathrm{C}$ & $2.12^{\circ} \mathrm{C}$ & 0.0002 & 0.0008 & 0.0001 & -0.13 \\
$\mathbf{3 . 0}{ }^{\circ} \mathrm{C}$ & $\mathbf{2 . 1 2}^{\circ} \mathrm{C}$ & $\mathbf{0 . 0 0 0 2}$ & $\mathbf{0 . 0 0 0 8}$ & $\mathbf{0 . 0 0 0 4}$ & $\mathbf{- 0 . 5 7}$ \\
$5.2^{\circ} \mathrm{C}$ & $2.12^{\circ} \mathrm{C}$ & 0.0004 & -0.0001 & -0.0002 & -1.83 \\
$7.0^{\circ} \mathrm{C}$ & $2.12^{\circ} \mathrm{C}$ & 0.0005 & -0.0003 & -0.0008 & -2.45 \\
& & & & & \\
$3.0^{\circ} \mathrm{C}$ & $1.53^{\circ} \mathrm{C}$ & 0.0002 & 0.0055 & 0.0047 & -0.87 \\
$\mathbf{3 . 0}^{\circ} \mathrm{C}$ & $\mathbf{2 . 1 2}^{\circ} \mathrm{C}$ & $\mathbf{0 . 0 0 0 2}$ & $\mathbf{0 . 0 0 0 8}$ & $\mathbf{0 . 0 0 0 4}$ & $\mathbf{- 0 . 5 7}$ \\
$3.0^{\circ} \mathrm{C}$ & $4.5^{\circ} \mathrm{C}$ & 0.0004 & -0.0165 & -0.0876 & -5.29 \\
$3.0^{\circ} \mathrm{C}$ & $3.5^{\circ} \mathrm{C}$ & 0.0003 & -0.0003 & -0.0067 & -18.42 \\
& & & & & \\
$2.0^{\circ} \mathrm{C}$ & $2.9214^{\circ} \mathrm{C}$ & 0.0002 & 0.0011 & 0.0003 & -0.34 \\
$3.8^{\circ} \mathrm{C}$ & $1.64{ }^{\circ} \mathrm{C}$ & 0.0002 & 0.0002 & 0.0008 & -4.58 \\
$4.122^{\circ} \mathrm{C}$ & $1.54{ }^{\circ} \mathrm{C}$ & 0.0002 & 0.0035 & 0.0087 & -2.44 \\
$\mathbf{3 . 0}^{\circ} \mathrm{C}$ & $\mathbf{2 . 1 2}^{\circ} \mathrm{C}$ & $\mathbf{0 . 0 0 0 2}$ & $\mathbf{0 . 0 0 0 8}$ & $\mathbf{0 . 0 0 0 4}$ & $\mathbf{- 0 . 5 7}$ \\
$1.0^{\circ} \mathrm{C}$ & $3.679^{\circ} \mathrm{C}$ & 0.0002 & -0.0013 & -0.0108 & -1.86 \\
\hline
\end{tabular}

Table 3.4: W.T.P, changes in $\mathcal{E}(T)$ and $S D(T) . \gamma=\mathcal{E}(\gamma)=0.0001363, \mathcal{E}(T)=3 . \quad \alpha=1, \beta=1.2, \theta=2.33$, $g_{0}=0.020$ and $\delta=0$.

3.4.13 W.T.P: $\mathcal{E}(T)$ and $S D(T): \mathcal{E}(T)=3$ : the case I.A.R.A and I.R.R.A: $\alpha>1, \beta>0$.

For parameter values of $\alpha=1.2, \beta=1.2, \theta=2.33, g_{0}=0.020$ and $\delta=0$, we are in the IARA/IRRA class. In Table 3.5, $\partial w^{*} / \partial \mathcal{E}(T)$ lies within -0.0016-0.0008 and $\partial w^{*} / \partial S D$ within $-0.0266-0.0341$, in such a way that the M.R.S lies within -17 and -47 . We can see occasional jumps in the M.R.S in Figure 3.21 for large values of standard deviation, which explains why sometimes averse people do not care about the certainty in the predictions of economic analysis. Although we get this result, in general the slope increases more significantly for small values of standard deviation, as above. 


\begin{tabular}{cccccc}
\hline $\mathcal{E}(T)$ & $S D(T)$ & $w^{*}(0)$ & $\partial w^{*} / \partial \mathcal{E}(T)$ & $\partial w^{*} / \partial S D$ & $M . R . S$ \\
\hline $1.2^{\circ} \mathrm{C}$ & $2.12^{\circ} \mathrm{C}$ & 0.0002 & 0.0008 & 0.0001 & -0.13 \\
$\mathbf{3 . 0}^{\circ} \mathrm{C}$ & $\mathbf{2 . 1 2}^{\circ} \mathrm{C}$ & $\mathbf{0 . 0 0 0 1 8}$ & $\mathbf{0 . 0 0 0 6}$ & $\mathbf{0 . 0 0 0 0 9}$ & $\mathbf{- 0 . 1 6}$ \\
$2.0^{\circ} \mathrm{C}$ & $2.12^{\circ} \mathrm{C}$ & 0.00015 & -0.0004 & -0.0018 & -4.39 \\
$7.0^{\circ} \mathrm{C}$ & $2.12^{\circ} \mathrm{C}$ & 0.0003 & -0.0006 & -0.0008 & -1.33 \\
& & & & & \\
$3.0^{\circ} \mathrm{C}$ & $1.53^{\circ} \mathrm{C}$ & 0.00016 & -0.0016 & -0.0266 & -16.31 \\
$\mathbf{3 . 0}^{\circ} \mathrm{C}$ & $\mathbf{2 . 1 2}^{\circ} \mathrm{C}$ & $\mathbf{0 . 0 0 0 1 8}$ & $\mathbf{0 . 0 0 0 6}$ & $\mathbf{0 . 0 0 0 0 9}$ & $\mathbf{- 0 . 1 6}$ \\
$3.0^{\circ} \mathrm{C}$ & $2.52^{\circ} \mathrm{C}$ & 0.00019 & 0.0008 & 0.0004 & -0.62 \\
$3.0^{\circ} \mathrm{C}$ & $2.30^{\circ} \mathrm{C}$ & 0.00019 & 0.0006 & 0.0001 & -0.32 \\
& & & & & \\
$3.57^{\circ} \mathrm{C}$ & $1.65^{\circ} \mathrm{C}$ & 0.00018 & 0.0008 & 0.0008 & -9.125 \\
$3.6^{\circ} \mathrm{C}$ & $1.6^{\circ} \mathrm{C}$ & 0.00018 & 0.00018 & 0.0006 & -3.71 \\
$1.8^{\circ} \mathrm{C}$ & $3.16^{\circ} \mathrm{C}$ & 0.00018 & 0.00018 & 0.0008 & -4.29 \\
$1.0^{\circ} \mathrm{C}$ & $3.75^{\circ} \mathrm{C}$ & 0.00018 & 0.0008 & 0.0341 & -42.18 \\
$\mathbf{3 . 0}^{\circ} \mathrm{C}$ & $\mathbf{2 . 1 2}^{\circ} \mathrm{C}$ & $\mathbf{0 . 0 0 0 1 8}$ & $\mathbf{0 . 0 0 0 6}$ & $\mathbf{0 . 0 0 0 0 9}$ & $\mathbf{- 0 . 1 6}$ \\
\hline
\end{tabular}

Table 3.5: W.T.P, changes in $\mathcal{E}(T)$ and $S D(T) . \gamma=\mathcal{E}(\gamma)=0.0001363, \mathcal{E}(T)=3 . \quad \alpha=1.2, \beta=1.2, \theta=2.33$, $g_{0}=0.020$ and $\delta=0$.

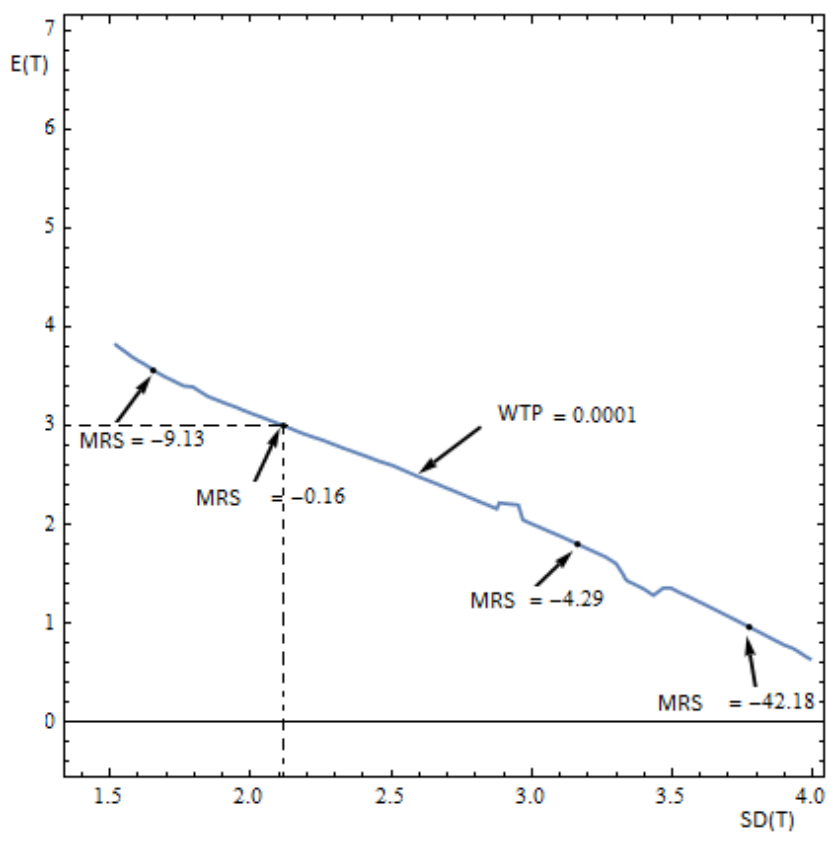

Figure 3.21: Iso-W.T.P curve, $w^{*}(0)=0.00018\left(\mathcal{E}(T)=3.0^{\circ} \mathrm{C}\right) ; \alpha=1.2, \beta=1.2, \theta=2.33, g_{0}=0.020$ and $\delta=0$.

\section{Discussion and Conclusions}

We resume the work of Pindyck [1] with the exception of the utility function and the ramifications generated from such a consideration. For a choice of conservative parameters ${ }^{22}$, we obtain values of $w^{*}(0)$ around $2.5 \%$ for the DARA/DRRA class, $0.3 \%$ for the DARA/IRRA class, $0.025 \%$ and $0.015 \%$ for the CARA/IRRA and IARA/IRRA classes. In the case of $w^{*}(3)$, limiting the temperature increase at the I.P.C.C's predicted value of $3^{\circ} \mathrm{C}$, these percentages are reduced; we get values of

\footnotetext{
${ }^{22}$ We take $\delta=0$ and $g_{0}=0.020$ as in Pindyck [1].
} 
$w^{*}(3)$ around $2 \%$ for the DARA/DRRA class , $0.2 \%$ for the DARA/IRRA class, $0.020 \%$ and $0.007 \%$ for the CARA/IRRA and IARA/IRRA classes respectively.

After this analysis, the remarkable result obtained is that, unless we are in the least averse class, increased utility discount rate does not necessarily lead to a W.T.P reduction; in fact, in the averse $\operatorname{classe}^{23}$, an increased utility discount rate increases the W.T.P, and much more, we have both scenarios in the DARA/IRRA class for an $\alpha$ parameterization threshold ( $\beta$ held constant).

It is rather intuitive that the less averse individual would sacrifice more and the more averse less, and this, without having to estimate the W.T.P in the different subclasses, gives a decreased W.T.P as aversion increases. Returning to the title of this paper, uncertainty and climate change policy; which, between uncertain and certain outcomes, have a greater influence on the W.T.P ?, the answer is uncertain outcomes. As Pindyck, we get decreasing iso-W.T.P curves with strong M.R.S values for small standard deviation values (and corresponding large means). Although there are occasional jumps of the M.R.S in averse classes for large standard deviation values (and corresponding small means), overall (as shown in the iso-W.T.P curves), the slope increases for small standard deviation values and corresponding large means, which is why we get strong M.R.S values in these regions. We can therefore conclude that, whatever be the class of aversion,uncertain outcomes affect more the W.T.P, are a greater enhancer of W.T.P, and thus, of climate policy. The W.T.P values obtained in this paper are consistent with a moderate climate policy. It is true that $2.5 \%$ of the G.D.P translates into a considerable monetary amount, but is justified if indeed we can limit any increase in temperature.

What proportion of consumption, if sacrificed, will be enough to limit future temperatures at a desired $\tau$ ?, or, what parameterization (for $\alpha, \beta$ and $\theta$ in the exponential utility function) is a perfect representation of the different aversion sub-classes ?. An answer to these questions will bring further clarifications to the modeling of this paper and lead to effective climate-policy reforms.

\section{References}

[1] Robert S Pindyck. Uncertain outcomes and climate change policy. Journal of Environmental Economics and management, 63(3):289-303, 2012.

[2] Atanu Saha. Expo-power utility: A 'flexible'form for absolute and relative risk aversion. American Journal of Agricultural Economics, 75(4):905-913, 1993.

[3] Charles D Kolstad. Fundamental irreversibilities in stock externalities. Journal of Public Economics, 60(2):221-233, 1996.

[4] Anthony C Fisher and Urvashi Narain. Global warming, endogenous risk, and irreversibility. Environmental and Resource Economics, 25(4):395-416, 2003.

[5] Charles D Kolstad. Learning and stock effects in environmental regulation: The case of greenhouse gas emissions. Journal of environmental economics and management, 31(1):1-18, 1996.

[6] Robert S Pindyck. Irreversibilities and the timing of environmental policy. Resource and energy economics, 22(3):233-259, 2000.

[7] Robert S Pindyck. Optimal timing problems in environmental economics. Journal of Economic Dynamics and Control, 26(9):1677-1697, 2002.

\footnotetext{
${ }^{23}$ DARA/IRRA, CARA/IRRA and IARA/IRRA.
} 
[8] Richard G Newell and William A Pizer. Regulating stock externalities under uncertainty. Journal of Environmental Economics and Management, 45(2):416-432, 2003.

[9] Robert S Pindyck. Uncertainty in environmental economics. Review of environmental economics and policy, 1(1):45-65, 2007.

[10] S Solomon, Dahe Qin, Martin Manning, Z Chen, M Marquis, KB Averyt, M Tignor, and HL Miller. Ipcc, climate change 2007: The physical science basis. Contribution of working group i to the fourth assessment report of the intergovernmental panel on climate change, 2007.

[11] T Wilbanks, PR Lankao, M Bao, F Berkhout, S Cairncross, JP Ceron, et al. Impacts, Adaptation, and Vulnerability. Contribution of Working Group II to the Fourth Assessment Report of the Intergovernmental Panel on Climate Change, Cambridge University Press, Cambridge, 2007.

[12] IPCC Climate Change. Mitigation of climate change. Summary for Policymakers, page 10, 2007.

[13] Rajendra K Pachauri, MR Allen, VR Barros, J Broome, W Cramer, R Christ, JA Church, L Clarke, Q Dahe, P Dasgupta, et al. Climate change 2014: Synthesis report. Contribution of Working Groups i, ii and iii to the Fifth Assessment Report of the Intergovernmental Panel on Climate Change. 2014.

[14] Martin L Weitzman. Additive damages, fat-tailed climate dynamics, and uncertain discounting. In The Economics of Climate Change: Adaptations Past and Present, pages 23-46. University of Chicago Press, 2011.

[15] Simon Dietz and Nicholas Stern. Why economic analysis supports strong action on climate change: a response to the stern review's critics. Review of Environmental Economics and Policy, 2(1):94-113, 2008.

[16] Robert S Pindyck. Modeling the impact of warming in climate change economics, in: G. Libecap, R. Steckel (Eds.), The Econommics of Climate Change. Technical report, University of Chicago Press, 2011.

[17] Robert S Pindyck. Fat tails, thin tails, and climate change policy. Review of Environmental Economics and Policy, 5(2):258-274, 2011.

[18] AP Sokolov, PH Stone, CE Forest, R Prinn, MC Sarofim, M Webster, S Paltsev, CA Schlosser, D Kicklighter, and S Dutkiewicz. Probabilistic forecast for 21st century climate based on uncertainties in emissions (without policy) and climate parameters. report no. 169. 2009. 